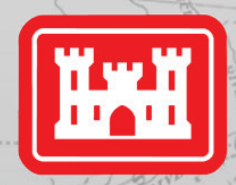

US Army Corps of Engineers ${ }_{\circledast}$

\section{Large-scale Geomorphic Change in the Mississippi River from St. Louis, MO, to Donaldsonville, LA, as Revealed by Specific Gage Records}

MRG\&P Report No. 10 • July 2017

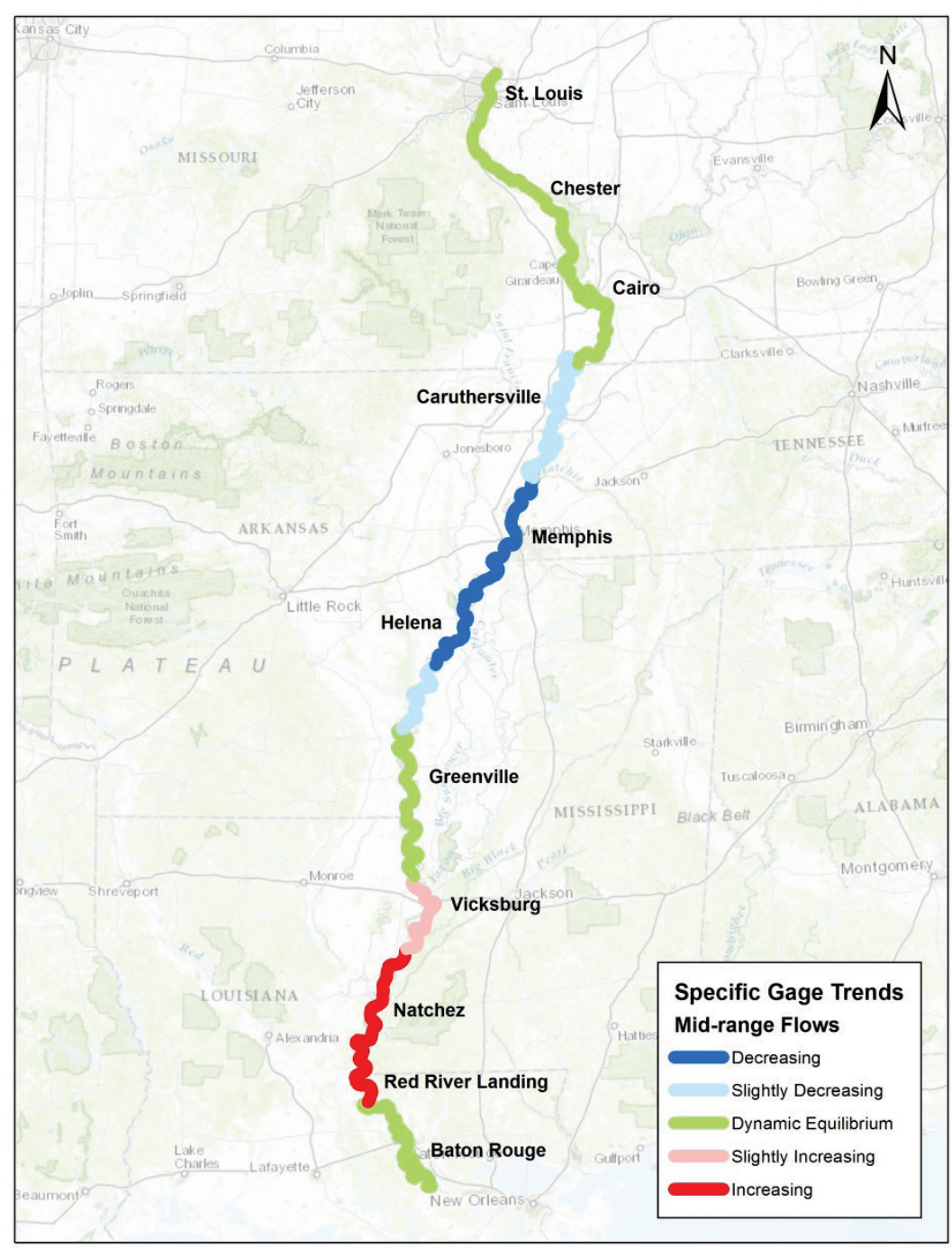

Mississippi River Geomorphology \& Potamology Program 


\section{Large-scale Geomorphic Change in the Mississippi River from St. Louis, MO, to Donaldsonville, LA, as Revealed by Specific Gage Records}

David S. Biedenharn

U.S. Army Engineer Research and Development Center

Coastal and Hydraulics Laboratory

3909 Halls Ferry Road

Vicksburg, MS 39180

Mead A. Allison

The Water Institute of the Gulf

301 North Main Street, Suite 2000

Baton Rouge, LA 70825

Charles D. Little, Jr.

Mendrop Resources Engineering, LLC

854 Wilson Drive

Suite $A$

Ridgeland, MS 39157

Colin R. Thorne

ESA Vigil-Agrimis

819 SE Morrison Street, Suite 310

Portland, OR 97214

Chester C. Watson

Biedenharn Group, LLC

3833 Teyside Court

Timnath, CO 80524

Final report

Approved for public release; distribution is unlimited.

Prepared for U.S. Army Corps of Engineers, Mississippi Valley Division Mississippi River Geomorphology and Potamology Program 1400 Walnut Street

Vicksburg, MS 39180

Under Project 127672; "Geomorphic Assessment of the Mississippi River" 


\section{Abstract}

Specific gage records were developed for 25 stations on the Mississippi River between St. Louis, MO, and Donaldsonville, LA. Generation and initial inspection of these records for the Mississippi River establish that complex morphologic adjustments have occurred throughout the river system for at least a century and indicate that these adjustments continue to the present day. Further, although no attempt was made in this study to conduct a detailed analysis of the effects of the numerous natural and anthropogenic factors on the morphologic trends in the river in the initial assessment reported herein, preliminary evaluation of the specific gage records demonstrates that they provide a powerful framework that, when combined with other geomorphic assessment tools, will aid in understanding and explaining the complex morphological processes that drive the Mississippi River. These and other comprehensive analyses are planned for future Mississippi River Geomorphology \& Potamology Program efforts.

DISCLAIMER: The contents of this report are not to be used for advertising, publication, or promotional purposes. Citation of trade names does not constitute an official endorsement or approval of the use of such commercial products. All product names and trademarks cited are the property of their respective owners. The findings of this report are not to be construed as an official Department of the Army position unless so designated by other authorized documents. 


\section{Contents}

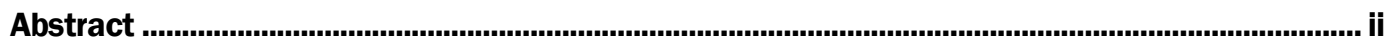

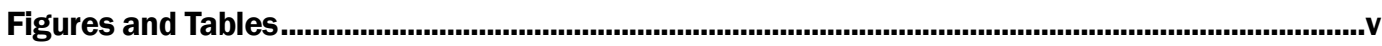

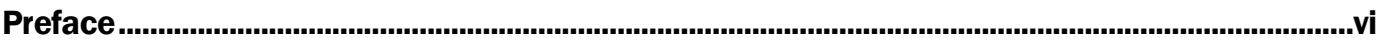

Unit Conversion Factors ......................................................................................................................vii

1 Background .............................................................................................................................. 1

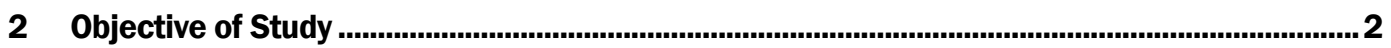

3 Specific Gage Analysis: Definition, Methods, and Limitations............................................ 3

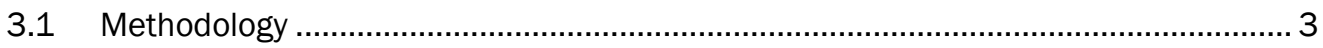

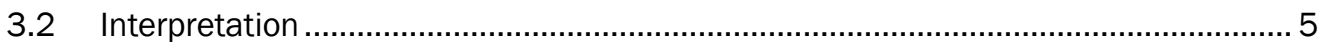

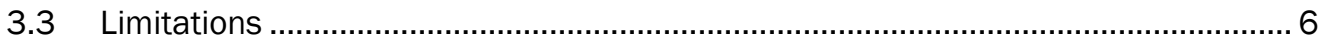

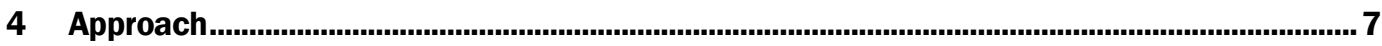

4.1 Development of specific gage records ............................................................. 7

4.2 Development of cumulative stage change curves................................................ 9

5 Specific Gage Records Available for the Mississippi River .......................................................11

5.1 Middle Mississippi river stations ................................................................. 11

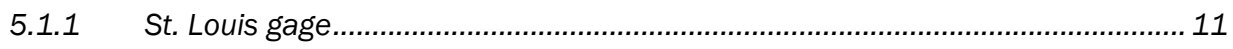

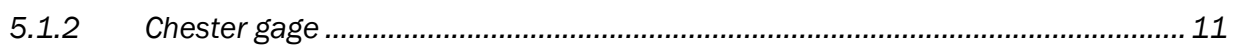

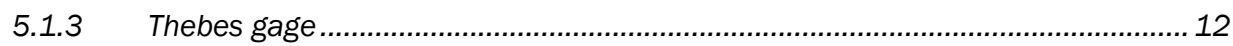

5.2 Lower Mississippi river stations .................................................................. 13

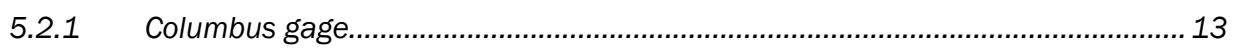

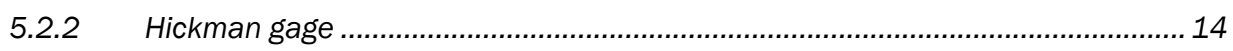

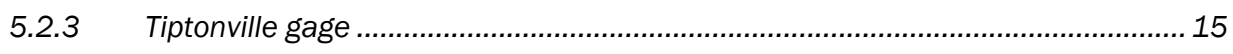

5.2.4 Caruthersville gage .......................................................................................... 16

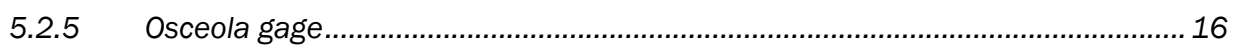

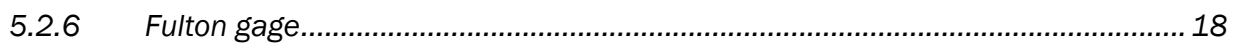

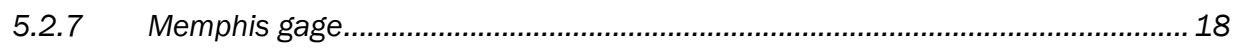

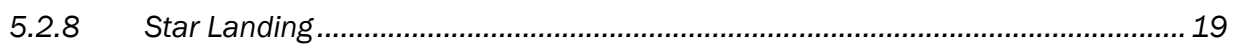

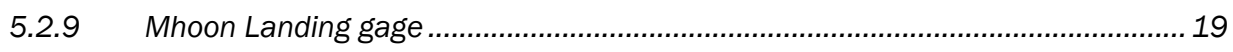

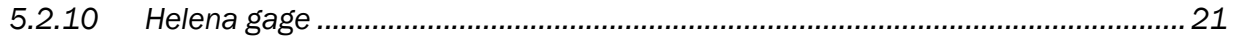

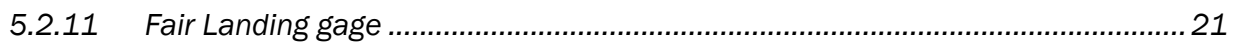

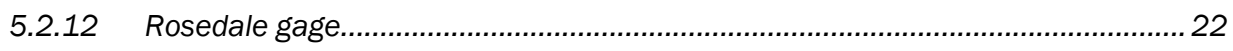

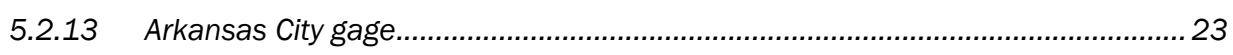

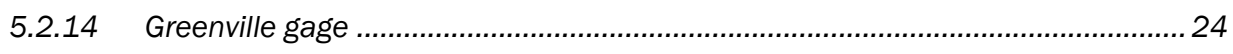

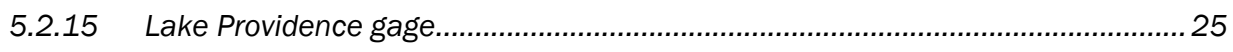

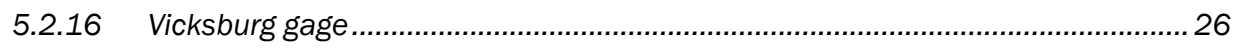

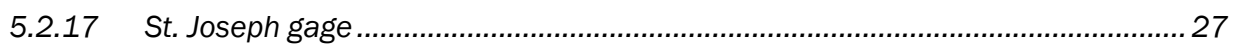




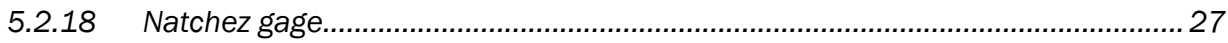

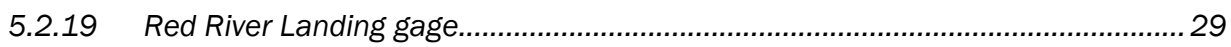

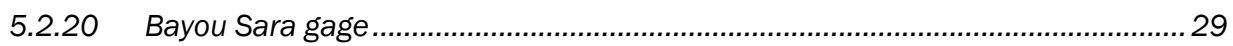

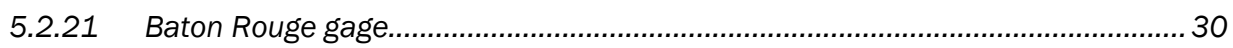

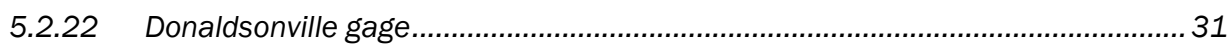

6 Discussion ...................................................................................................................................33

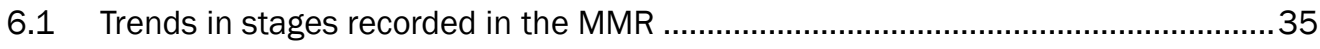

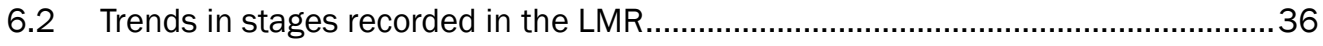

6.2.1 Trends in stages recorded in the upper course of the LMR ....................................36

6.2.2 Trends in stages recorded in the lower course of the LMR .................................. 38

6.2.3 Overview of post-cutoff trends in stages in the $L M R$......................................... 38

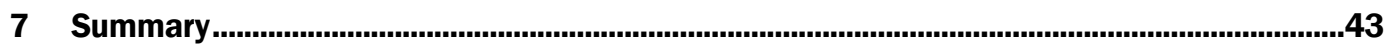

References ..................................................................................................................................................44

Report Documentation Page 


\section{Figures and Tables}

\section{Figures}

Figure 4.1. Location of Mississippi River hydrometric stations.. .8

Figure 5.1. Specific gage record for St. Louis, MO (RM 179.6 on the MMR)....................................12

Figure 5.2. Specific gage record for Chester, IL (RM 109.9 on the MMR). ........................................12

Figure 5.3. Specific gage record for Thebes, IL (RM 43.7 on the MMR) ............................................13

Figure 5.4. Specific gage record for Columbus, KY (RM 937.2 AHP on the LMR).............................14

Figure 5.5. Specific gage record at Hickman, KY (RM 922 AHP on the LMR)...................................15

Figure 5.6. Specific gage record at Tiptonville, TN (RM 872.4 AHP on the LMR)...........................16

Figure 5.7. Specific gage record at Caruthersville, TN (RM 844.4 AHP on the LMR).......................17

Figure 5.8. Specific gage record at Osceola, TN (RM 783.5 AHP on the LMR)................................17

Figure 5.9. Specific gage record at Fulton, TN (RM 778.2 AHP on the LMR)...................................18

Figure 5.10. Specific gage record at Memphis, TN (RM 734.7 AHP on the LMR)...........................19

Figure 5.11. Specific gage record at Star Landing, MS (RM 707.2 AHP on the LMR)......................20

Figure 5.12. Specific gage record at Mhoon Landing, MS (RM 687.5 AHP on the LMR)..................20

Figure 5.13. Specific gage record at Helena, AR (RM 663 AHP on the LMR)...................................21

Figure 5.14. Specific gage record at Fair Landing, AR (RM 632.5 AHP on the LMR)......................22

Figure 5.15. Specific gage record at Rosedale, MS (RM 592.2 AHP on the LMR)..........................23

Figure 5.16. Specific gage record at Arkansas City, AR (RM 554.1 AHP on the LMR)......................24

Figure 5.17. Specific gage record at Greenville, MS (RM 531.5 AHP on the LMR)..........................25

Figure 5.18. Specific gage record at Lake Providence, LA (RM 487.2 AHP on the LMR)..................26

Figure 5.19. Specific gage record at Vicksburg, MS (RM 435.7 AHP on the LMR)...........................27

Figure 5.20. Specific gage record at St. Joseph, LA (RM 396.4 AHP on the LMR)...........................28

Figure 5.21. Specific gage record at Natchez, MS (RM 363.3 AHP on the LMR).............................28

Figure 5.22. Specific gage record at Red River Landing, LA (RM 302.4 AHP on the LMR)..............29

Figure 5.23. Specific gage record at Bayou Sara, LA (RM 265.4 AHP on the LMR).........................30

Figure 5.24. Specific gage record at Baton Rouge, LA (RM 228.4 AHP on the LMR).....................31

Figure 5.25. Specific gage record at Donaldsonville, LA (RM 175.4 AHP on the LMR)....................32

Figure 6.1. Cumulative specific gage stage change curves for low flows at 12 stations

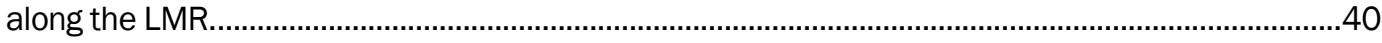

Figure 6.2. Cumulative specific gage stage change curves for high flows at 12 stations

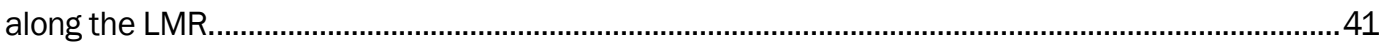

Figure 6.3. Broad-scale stage trends along the Mississippi River...................................................42

\section{Tables}

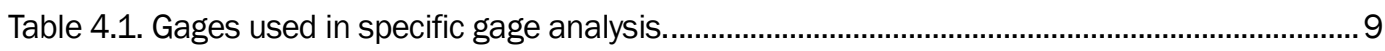

Table 6.1. General stage trends on the Mississippi River in the post-cutoff period. .........................34 


\section{Preface}

The research documented in this report was conducted as part of the Mississippi River Geomorphology \& Potamology (MRG\&P) Program, Project 127672; "Geomorphic Assessment of the Mississippi River." The MRG\&P is part of the Mississippi River and Tributaries Program and is managed by the U.S. Army Corps of Engineers (USACE), Mississippi Valley Division (MVD), and Districts. The MRG\&P Senior Program Manager was Mr. Freddie Pinkard, and the Technical Director was Dr. Barbara Kleiss. The MVD Commander was MG Michael C. Weir. The MVD Director of Programs was Mr. James A. Bodron.

Mississippi River engineering direction and policy advice were provided by the Mississippi River Commission. The Commission members were MG Wehr, USACE; the Honorable Sam E. Angel; the Honorable R. D. James; the Honorable Norma Jean Mattei, Ph.D.; RDML Gerd F. Glang, National Oceanic and Atmospheric Administration; BG Richard G. Kaiser, USACE; and BG David C. Hill, USACE.

The investigation was conducted by a collaboration among the following offices and agencies: MVD, St. Louis District, Memphis District, Vicksburg District, New Orleans District, and the U.S. Army Engineer Research and Development Center (ERDC), Coastal and Hydraulics Laboratory (CHL). Funding for the study was provided by MVD.

Direct supervision of the CHL aspects of this effort was provided by Dr. Ty Wamsley, Chief of the Flood and Storm Division (CERD-HF), and Dr. James Lewis, acting Chief of the River Engineering Branch (CERDHFR). The Deputy Director of CHL was Mr. Jeffrey Eckstein, and the Director of CHL was Mr. José E. Sánchez.

The Commander of ERDC was COL Bryan S. Green, and the Director of ERDC was Dr. David W. Pittman. 


\section{Unit Conversion Factors}

\begin{tabular}{|c|c|c|}
\hline Multiply & By & To Obtain \\
\hline cubic feet & 0.02831685 & cubic meters \\
\hline feet & 0.3048 & meters \\
\hline miles (U.S. statute) & $1,609.347$ & meters \\
\hline
\end{tabular}




\section{Background}

The development of the Mississippi River and its floodplain for navigation and flood control has been ongoing since the eighteenth century, with the most concerted efforts occurring as a result of the Flood Control Act (FCA) of 1928 (U.S. Congress 1928) following the Great Flood of 1927. The Mississippi River and Tributaries Project that was spawned from the FCA of 1928 has produced a massive, comprehensive system for flood control and channel stabilization that includes levees, channel improvements, and floodways, as well as tributary reservoirs and other basin improvements (Moore 1972). Additionally, the development of the river for safe and dependable navigation has generated a substantial engineering effort involving river training structures, meander cutoffs, and dredging. The historical, present-day, and future morphology of the Mississippi River reflects an integration of all these engineering interventions (and the process-responses they have triggered in the fluvial system) combined with natural drivers of channel change and evolution, including floods and droughts, hurricanes, neotectonic activity, geologic outcrops, climatic variability, climate change, and relative sea-level rise. Understanding how these various factors affect river morphology and its short- and long-term evolution is a complex challenge that must be addressed by the river engineers and scientists responsible for managing this system for flood control, navigation, and habitat.

With the complex requirements in navigation, flood risk reduction, and environmental restoration, all with multiple stakeholders, future Mississippi River management will require the most advanced knowledge available. The Mississippi River Geomorphology \& Potamology (MRG\&P) Program was developed in recognition of this challenge. The MRG\&P Program is a joint effort of the U.S. Army Corps of Engineers (USACE), St. Louis, Memphis, Vicksburg, and New Orleans Districts and was conducted with the oversight of the Mississippi Valley Division (MVD) and benefiting from technical contributions from the U.S. Army Engineer Research and Development Center. The study reported herein is just one of many components of the MRG\&P Program. 


\section{Objective of Study}

The objective of this study was to develop specific gage records at all major gage locations along the Lower Mississippi River and the Middle Mississippi River. Specific gage records were developed for the entire period of record available at each gage, using the direct step method (Watson et al. 2013). These records were developed to serve as a framework for more detailed geomorphic analyses that integrate multiple historical river records (e.g., channel bathymetric mapping, sediment load records, substrate evolution) to be conducted as part of the ongoing MRG\&P efforts. It was not the objective of this study to conduct the detailed interpretation of the gage record trends necessary to identify specific cause-and-effect relationships. However, general increasing and decreasing stage trends were identified at each gage, and preliminary assessment of their implications was undertaken. 


\section{Specific Gage Analysis: Definition, Methods, and Limitations}

Specific gage analysis is a powerful tool used by river engineers and scientists needing to assess the historical behavior of rivers, and it has been so for several decades. Blench (1966) described specific gage records as follows:

There is no single sufficient test whether a channel is in-regime. However, for rivers, the most powerful single test is to plot curves of 'specific gage' against time; if the curves neither rise nor fall consistently the channel is in-regime in the vicinity of the gaging site for most practical purposes.

A detailed description of specific gage analysis is provided by Watson et al. (2013), and the main points made in that paper are briefly summarized in the remainder of this chapter.

\subsection{Methodology}

Fundamentally, a specific gage record can be developed by one of two methods. The first is referred to as the rating curve method and the second as the direct step method. In the rating curve method, the first step is to establish the stage-discharge relationship at the gage for each year in the period of record that is being analyzed. A best-fit curve is then plotted through the data, either by eye or through application of an appropriate curve-fitting method, such as regression. As the specific gage record reflects only observed data, it is important that the best fit or regression line is not extrapolated beyond the limits of the measured data for the particular year of observation. Often, there are years within which no gaged discharges were measured for very high or very low discharges, either because such discharges did not occur or because if they did, they were not gaged. In such years, there will be a gap in the specific gage record for very high and/or very low discharges that year. Computed daily discharge values are sometimes used to increase the number of data points and improve the statistics of the rating curve. While this generates additional data points, this practice is typically discouraged as it adds no 
explanatory power to the statistical relationship between stage and discharge for that year. After the rating curves for each year have been developed, stages are determined for each specified discharge and plotted for that year on the specific gage plot.

In contrast, in the direct step method, specific gage data are not obtained from an annual rating curve but instead come directly from the discharge measurements. The first step in the direct step method is to select a bin size for the gaged discharges. There is no "correct" bin size, and the investigator must select this based on experience, but bin sizes typically range from approximately $\pm 2.5 \%$ to $\pm 5 \%$ of the discharge. For example, if a bin size of $\pm 2.5 \%$ is selected, a flow of $1,000,000$ cubic feet (cfs) would represent all the gaged discharges between 975,000 cfs and 1,025,000 cfs.

In the second step, stage values observed within the selected discharge ranges are plotted against the date of measurement to produce a specific gage record. Hence, while the rating curve method produces only a single stage for each discharge in each year, the direct step method may produce several stages for a given discharge depending on the number of discharge and stage measurements made in that year.

Both the rating curve and direct step methods are acceptable approaches to performing a specific gage analysis. Each method has its advantages and disadvantages, and the investigator must decide which method to use based on the context for the particular study and the data available to support specific gage analysis.

Advantages of the rating curve method include that it

1. allows development of specific gage records for any flow within the range of flows measured for a particular year

2. produces relatively smooth stage-discharge curves that are easy to interpret visually.

Disadvantages of the rating curve method include that it

1. relies on having sufficient data to develop a reliable rating curve for each year

2. generates only a single data point for each year, which masks the variability of the actual measurements made during that year 
3. bases the specific gage record on a regression curve fitted to the data, making the statistical analysis of trends less robust than is the case for the direct step method.

Advantages of the direct step method include that it

1. is quick and easy to perform

2. allows for more robust statistical analysis

3. shows the individual measurements - which means that the variability in the data is apparent to both those performing the analysis and end users of that analysis.

Disadvantages of the direct step method are that

1. the records sometimes include a lot of scatter, which makes for highly irregular stage-discharge curves

2. it is only possible to derive specific gage records for those discharges that were actually measured in a particular year, which may lead to gaps in the record for some flows.

\subsection{Interpretation}

While the creation of a specific gage record is a relatively simple, straightforward procedure, interpretation of a specific gage record can be more challenging. This is the case because reliable interpretation requires both insight and appropriate judgement-based decision-making on the part of the investigator. Good examples of this may be drawn from consideration of the time period over which trends in stages associated with a specified discharge are deemed to be significant.

Selecting the appropriate time scale for identifying trends is important because, typically, specific gage records exhibit considerable variability, with stages for a given discharge scattered around the time-averaged, mean value. Characteristically, this variability is not random: stages that vary cyclically are commonly encountered. Consequently, a short-term trend in the specific gage record may not reflect progressive change in the morphology of the river, being instead part of the between peaks and troughs that constitute the upper and lower boundaries of a band of variability about a steady, time-averaged mean value. In such cases, the period of which trends are identified needs to be lengthened to cover at 
least one cycle of the variation that occurs within what may be considered to be dynamic equilibrium.

Conversely, trending over too long a time scale may also lead to misinterpretation of stage changes associated with a given discharge. This is because identifying trends over multiple decades may mask changes associated with one (or several) shorter periods of relatively rapid morphological response to disturbance of the fluvial system by, for example, a major flood or a dredging project. The risk here is that the impact of abrupt channel changes on the stage-discharge relationship may be obscured when a trend line is fitted over a prolonged period. In such circumstances, the period of record should be divided into two or more shorter periods in order to reveal real, short-term trends.

Another potential pitfall is to interpret a change in the stage-discharge relationship as always being indicative of a change in the elevation of the channel bed. In this context, it is important to recognize that specific gage records actually track changes in water surface elevation. While a change in the stage for a specific discharge may reflect a change in the elevation of the bed of the river (due to degradation or aggradation), it may also result from some other change in channel properties, roughness being a good example.

\subsection{Limitations}

As is the case for any river engineering tool, there are limitations to specific gage analysis that must be recognized. Perhaps the two most significant limitations stem from the context of the analysis in space and time. In particular, the following should be noted.

1. A specific gage record depicts conditions and changes within the reach around the particular hydrometric station being assessed, and these may not be representative of conditions farther upstream or downstream in the river.

2. Specific gage records chart the historical behavior of the river during the period of record. Extrapolation of specific gage curves into the future is risky and is generally not to be recommended. 


\section{Approach}

The methods used to develop the specific gage records and cumulative stage change curves are discussed in this chapter.

\subsection{Development of specific gage records}

Specific gage records were developed for 25 hydrometric stations between St. Louis, MO, and Donaldsonville, LA. No specific gage records were developed for the major tributaries although this effort is being considered as part of the MRG\&P Program long-term plans. Both the direct step and the rating curve methods are acceptable methods; however, for this study, the direct step method was selected in order to provide some view of the variability in the data. A bin range of $\pm 2.5 \%$ was used. There are two types of gages on the Mississippi River:

1. primary stations (stage and discharge)

2. secondary stations (daily stage only).

Observed stages and measured (gaged) discharges are available for the primary stations. However, at the secondary stations, no discharge measurements are made, and for these stations, stages (observed and recorded daily) were correlated with discharges measured at the closest primary station. The discharges measured at a hydrometric station located some distance away from a primary station may differ from that at the station due to lag effects associated with the rising and falling limbs of a hydrograph, and this introduces uncertainty into the relationship between stage and discharge developed from the stage record for a secondary station. The level of uncertainty increases with the distance between the stations and hydrologic variability in the intervening reach. Additional care should be exercised when interpreting results from secondary stations. However, on the Mississippi River, confidence in the observed stages and remotely-measured discharges they provide is sufficiently high for these stations to supply stage-discharge data that usefully supplement primary station data. 
The locations of hydrometric stations on the Mississippi River are shown in Figure 4.1. Table 4.1 lists the location (river mile [RM]), type of station, associated discharge station, and period of record. For the Middle Mississippi River (MMR), RMs are measured upstream from the confluence with the Ohio River. For the Lower Mississippi River (LMR), RMs are measured Above Head of Passes (AHP).

Figure 4.1. Location of Mississippi River hydrometric stations.

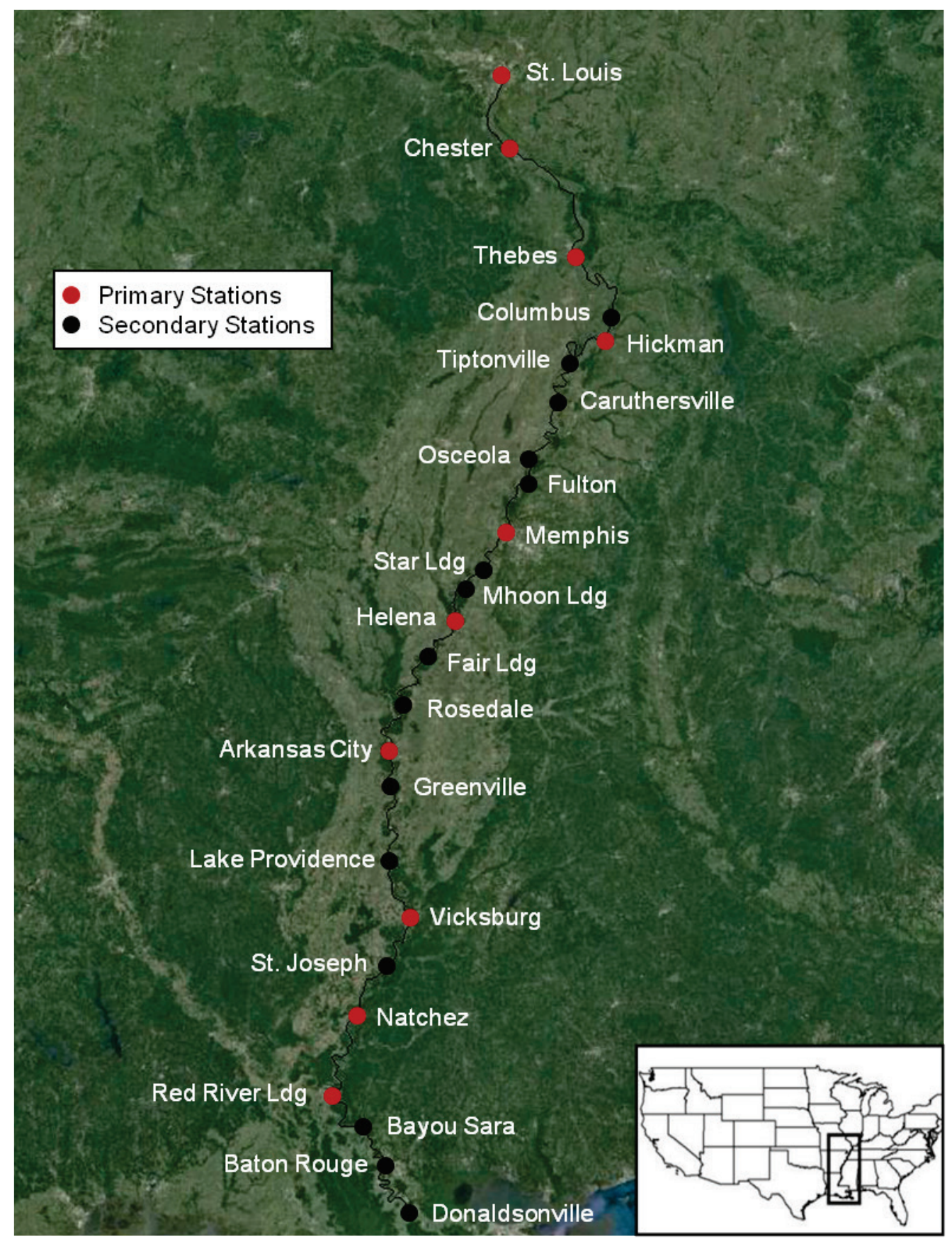


Table 4.1. Gages used in specific gage analysis.

\begin{tabular}{|c|c|c|c|c|c|c|c|}
\hline \multirow{2}{*}{\begin{tabular}{|l|} 
Reach \\
MMR \\
\end{tabular}} & \multicolumn{3}{|c|}{ Station Name } & \multirow{2}{*}{\begin{tabular}{|l|}
$\begin{array}{l}\text { Location } \\
\text { (RM)* }\end{array}$ \\
179.6
\end{tabular}} & \multirow{2}{*}{\begin{tabular}{|l}
$\begin{array}{l}\text { Station } \\
\text { Type }\end{array}$ \\
Primary
\end{tabular}} & \multirow{2}{*}{\begin{tabular}{|l|}
$\begin{array}{l}\text { Discharge } \\
\text { Station }\end{array}$ \\
St. Louis \\
\end{tabular}} & \multirow{2}{*}{\begin{tabular}{|l}
$\begin{array}{l}\text { Period of } \\
\text { Record }\end{array}$ \\
$1933-2014$ \\
\end{tabular}} \\
\hline & 1 & St. Louis & MO & & & & \\
\hline & 2 & Chester & $\mathrm{IL}$ & 109.9 & Primary & Chester & $1942-2014$ \\
\hline & 3 & Thebes & IL & 43.7 & Primary & Thebes & $1941-2014$ \\
\hline \multirow[t]{22}{*}{ LMR } & 4 & Columbus & KY & 937.2 & Secondary & Hickman & $1857-2013$ \\
\hline & 5 & Hickman & $\mathrm{KY}$ & 922 & Primary & Hickman & $1931-2013$ \\
\hline & 6 & Tiptonville & $\mathrm{TN}$ & 872.4 & Secondary & Hickman & $1930-2013$ \\
\hline & 7 & Caruthersville & $\mathrm{TN}$ & 844.4 & Secondary & Hickman & $1930-2013$ \\
\hline & 8 & Osceola & $\mathrm{TN}$ & 783.5 & Secondary & Memphis & $1930-2013$ \\
\hline & 9 & Fulton & $\mathrm{TN}$ & 778.2 & Secondary & Memphis & $1930-1990$ \\
\hline & 10 & Memphis & $\mathrm{TN}$ & 734.7 & Primary & Memphis & $1882-2014$ \\
\hline & 11 & Star Landing & MS & 707.2 & Secondary & Memphis & $1930-1991$ \\
\hline & 12 & Mhoon Landing & MS & 687.5 & Secondary & Memphis & $1930-1981$ \\
\hline & 13 & Helena & AR & 663 & Primary & Helena & $1882-2014$ \\
\hline & 14 & Fair Landing & AR & 632.5 & Secondary & Helena & $1934-2001$ \\
\hline & 15 & Rosedale & MS & 592.2 & Secondary & Helena & 1940-2014 \\
\hline & 16 & Arkansas City & AR & 554.1 & Primary & Arkansas City & $1884-2014$ \\
\hline & 17 & Greenville & MS & 531.5 & Secondary & Arkansas City & $1941-2014$ \\
\hline & 18 & Lake Providence & LA & 487.2 & Secondary & Vicksburg & $1906-2014$ \\
\hline & 19 & Vicksburg & MS & 435.7 & Primary & Vicksburg & $1858-2014$ \\
\hline & 20 & St. Joseph & LA & 396.4 & Secondary & Natchez & $1935-1996$ \\
\hline & 21 & Natchez & MS & 363.3 & Primary & Natchez & $1890-2014$ \\
\hline & 22 & Red River Landing & LA & 302.4 & Primary & Tarbert Landing & $1943-2015$ \\
\hline & 23 & Bayou Sara & LA & 265.4 & Secondary & Tarbert Landing & $1963-2015$ \\
\hline & 24 & Baton Rouge & $\mathrm{LA}$ & 228.4 & Secondary & Tarbert Landing & $1963-2015$ \\
\hline & 25 & Donaldsonville & LA & 175.4 & Secondary & Tarbert Landing & $1963-2015$ \\
\hline
\end{tabular}

* MMR RMs are measured upstream of the confluence with the Ohio River whereas LMR RMs are measured AHP.

\subsection{Development of cumulative stage change curves}

Given the length of the LMR, the large number of stations, and complexity of trends, it was decided to display stage changes using cumulative stage change curves, plotted on the same graph for all the main stations on the LMR (plots are presented in the "Discussion" chapter). These cumulative 
curves provide a compact means of visualizing relative stage changes at stations along the LMR.

The cumulative curves were developed through a series of computational steps.

1. A start year was selected for the post-cutoff period, for which the cumulative change would be set to zero. The LMR meander bend cut-offs were constructed between 1929 and 1942 and represent a period of dramatic morphological adjustments along the river (Winkley 1977). After inspecting the specific gage records for stations in the LMR, 1960 was designated as beginning of the post-cutoff period. Note that because of limited data, particularly at the high flows, the start date for some stations had to be set as far back as the early-1950s.

2. The second step in the development of the cumulative curves was to take the average of the observed stages for each year for the selected discharge.

3. Stage changes between successive years were calculated, and the cumulative curves were developed by summing the average stage change values between successive measurements.

4. A locally weighted scatterplot smoothing (LOESS) technique was used to draw smooth curves through the data (Cleveland and Devlin 1988). The smoothed curves provide an easy way to observe periodic cycles of increasing or decreasing trends and allow determination of the approximate cumulative stage change at any point in time. 


\section{Specific Gage Records Available for the Mississippi River}

In this chapter, the specific gage record for each station is presented, and overall stage trends for the period of record are briefly described. Neither detailed assessments nor statistical analyses of trends are reported, nor are the trends attributed to specific natural or anthropogenic factors such as changes in the hydrologic regime and/or basin sediment supply or construction of features (dikes, revetments, cutoffs, levees, dams, or diversions). These and other comprehensive analyses are planned for future MRG\&P Program efforts.

\subsection{Middle Mississippi river stations}

\subsubsection{St. Louis gage}

The St. Louis gage is a primary station located at RM 179.6 on the MMR, upstream from its confluence with the Ohio River. The period of record for the specific gage analysis extends from 1933 to 2014 (Figure 5.1). Bankfull stage is 30 feet ( $\mathrm{ft}$ ) on the St. Louis gage. As shown in Figure 5.1, there is a general decreasing stage trend at the two lower flows $(100,000 \mathrm{cfs}$ and $200,000 \mathrm{cfs}$ ) from the early-1930s to 2014. At higher flows (300,000 cfs and greater), there are fluctuations in stage, but overall, stages have remained relatively stable during the period of record.

\subsubsection{Chester gage}

The Chester gage is a primary station located at RM 109.9 on the MMR, upstream from its confluence with the Ohio River. The period of record for the specific gage analysis extends from 1942 to 2014 (Figure 5.2). Bankfull stage is $27 \mathrm{ft}$ on the Chester gage. As shown in Figure 5.2, there is a slight, decreasing trend in stage for the lowest discharge (100,000 $\mathrm{cfs})$. Stages for $200,000 \mathrm{cfs}$ and $300,000 \mathrm{cfs}$ have exhibited some fluctuations but have been relatively stable during the period of record. Stages for the highest flows (500,000 cfs and 650,000 cfs) have increased slightly, with their upward trend becoming most pronounced since the late-1980s. 
Figure 5.1. Specific gage record for St. Louis, MO (RM 179.6 on the MMR).

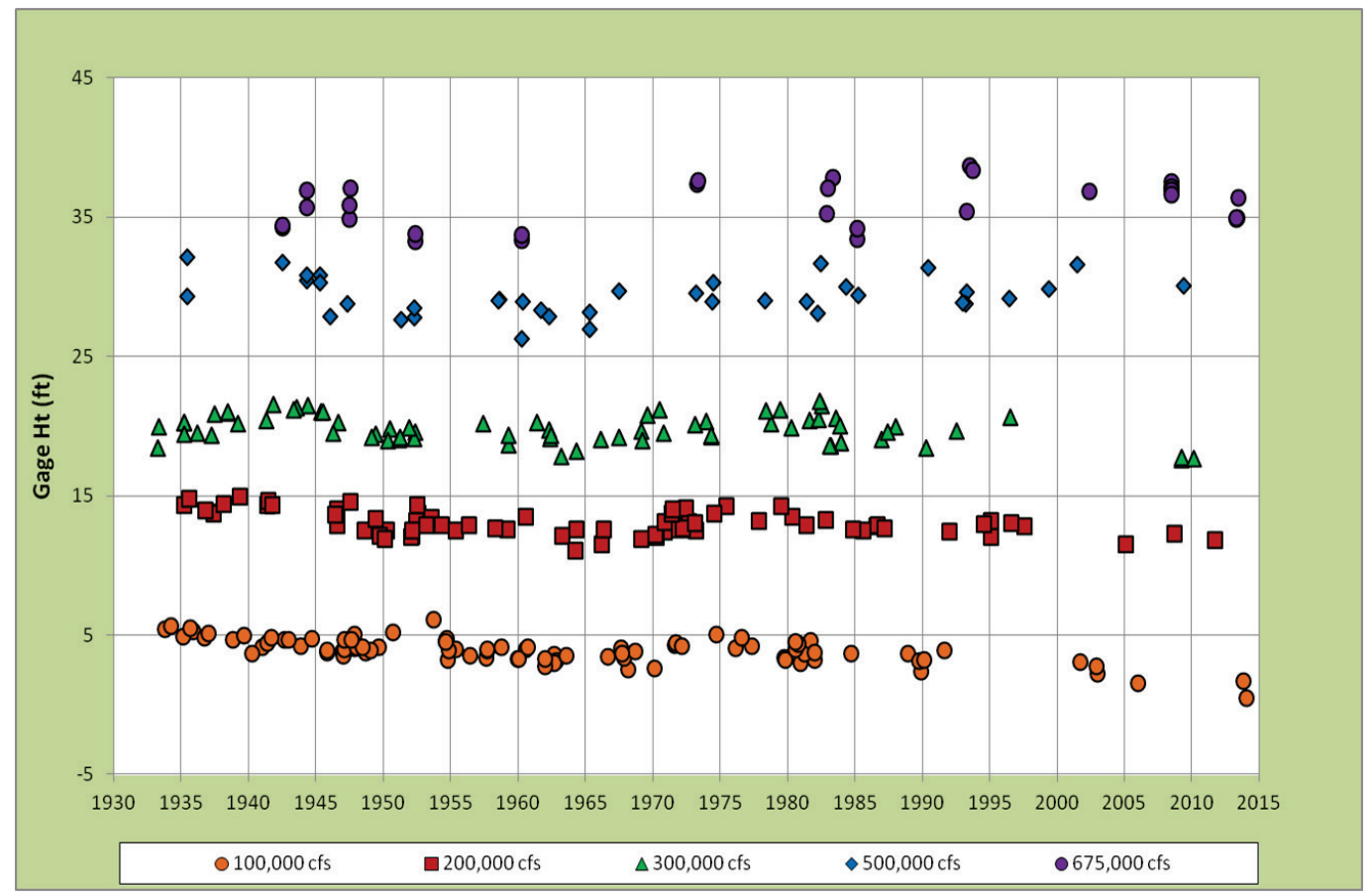

Figure 5.2. Specific gage record for Chester, IL (RM 109.9 on the MMR).

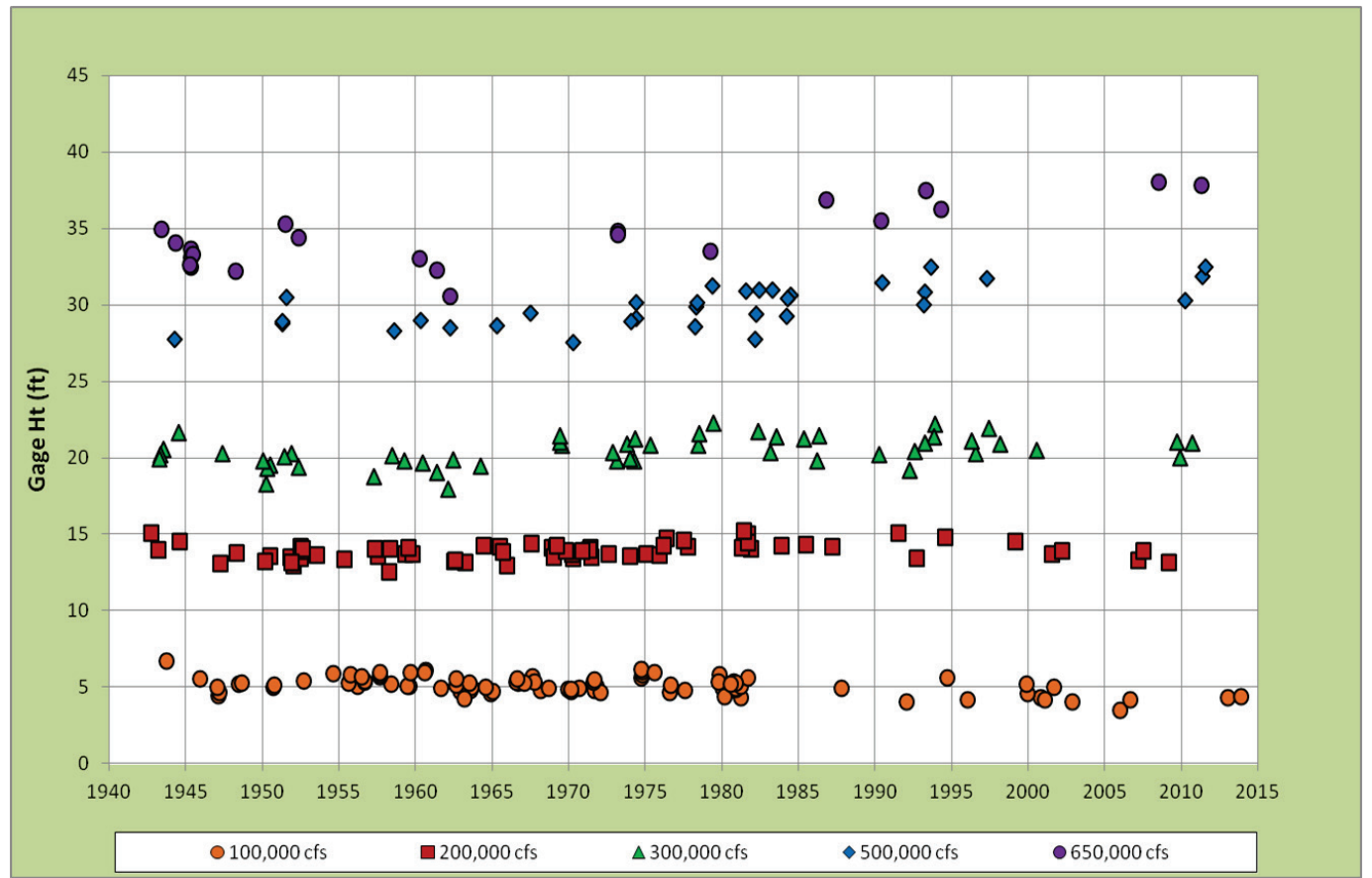

\subsubsection{Thebes gage}

The Thebes gage is a primary station located at RM 43.7 on the MMR, upstream of its confluence with the Ohio River. The period of record for the specific gage analysis extends from 1941 to 2014 (Figure 5•3). Bankfull 
stage is $33 \mathrm{ft}$ on the Thebes gage. Because of its close proximity to the (larger) Ohio River, the Thebes gage is periodically subject to backwater effects. Therefore, an attempt was made to remove as many of these backwater-affected measurements as possible. This was accomplished by removing all measurements where the stage difference between Thebes and Cairo was less than $15 \mathrm{ft}$. As shown in Figure 5.3, for the lowest discharge $(98,000 \mathrm{cfs})$ there has been a general decreasing trend in stage during the period of record. Conversely, stages for the highest (overbank) flow of $650,000 \mathrm{cfs}$, appear to show an overall increasing trend that started in the early-1940s and continues through to 2014. Stages for $500,000 \mathrm{cfs}$ exhibit a slightly increasing trend through to approximately the year 2000. Two measurements in 2010 suggest a possible decrease in stage, but these limited data are insufficient to establish whether this is evidence of a longer term trend or simply a short-term phenomenon. Stages for mid-range flows (200,000 cfs and 300,000 cfs) have been relatively stable over the period of record, while fluctuating cyclically.

Figure 5.3. Specific gage record for Thebes, IL (RM 43.7 on the MMR).

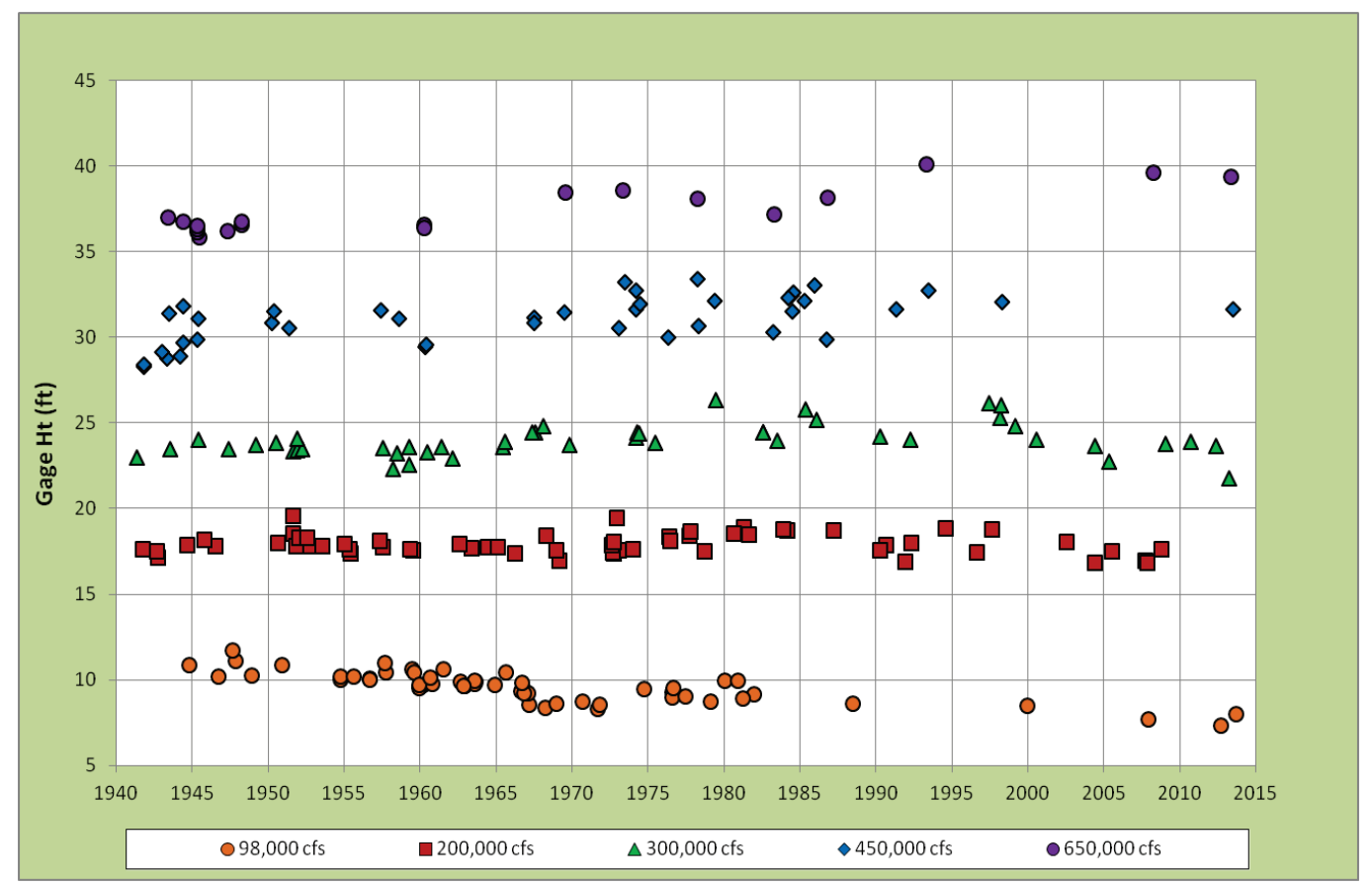

\subsection{Lower Mississippi river stations}

\subsubsection{Columbus gage}

Columbus is a secondary station located at RM 937.2 AHP on the LMR, making it the gage farthest upstream on the lower river. Measured 
discharge data for this gage come from Hickman, which is approximately 15 miles downstream. The long period of record for the specific gage analysis extends from 1857 to 2013 (Figure 5.4). Bankfull stage is $43 \mathrm{ft}$ on the Columbus gage. As shown in Figure 5.4, stages generally increased prior to the early-1930s, trends being more pronounced at higher flows than at lower flows. Post-1930s stages are relatively stable with perhaps a very slight increasing trend at flows above bankfull stage and a very slight decreasing trend at lower flows.

Figure 5.4. Specific gage record for Columbus, KY (RM 937.2 AHP on the LMR).

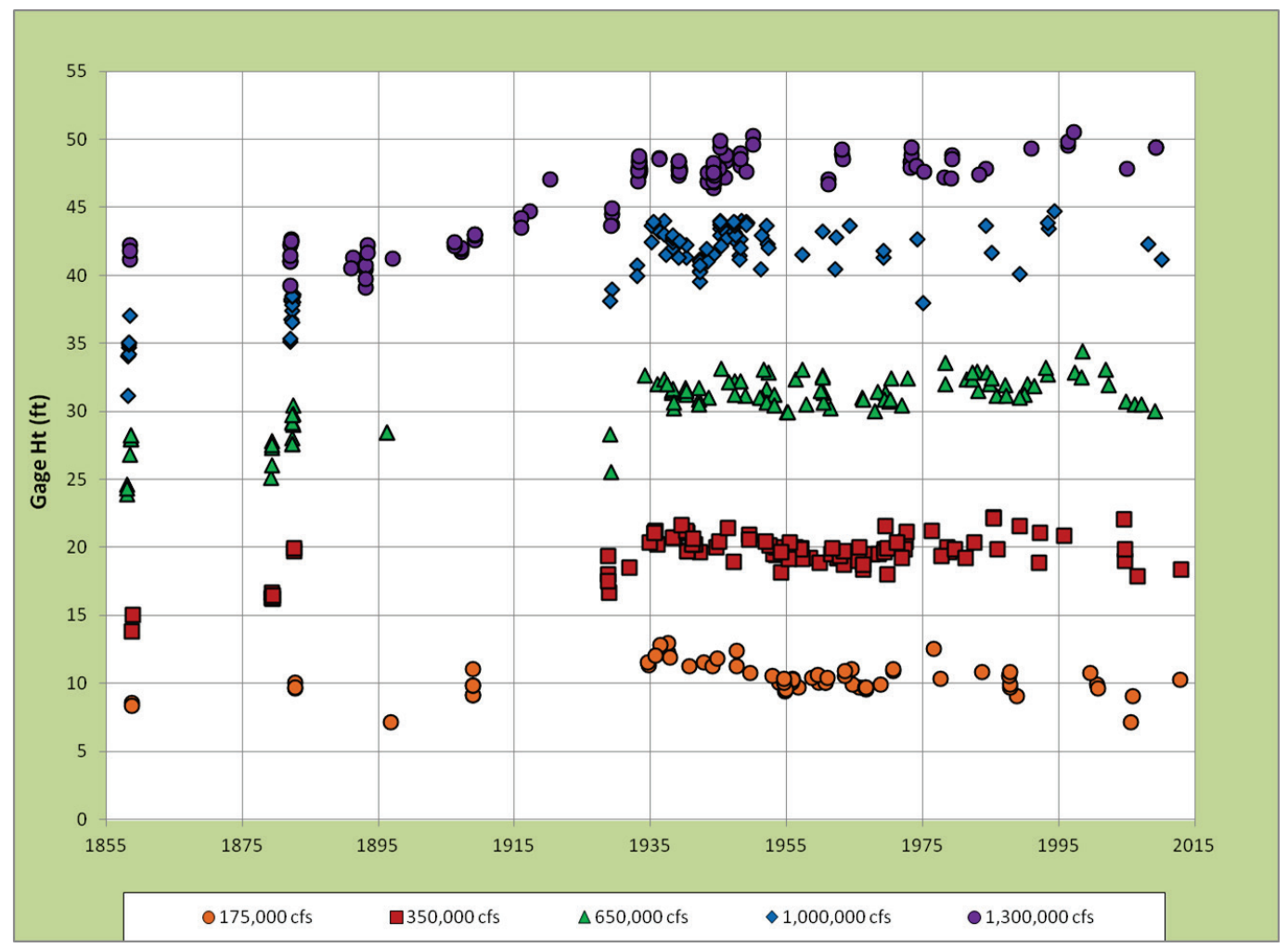

\subsubsection{Hickman gage}

Hickman is a primary station located at RM 922 AHP on the LMR. The period of record for the specific gage analysis extends from 1931 to 2013 (Figure 5.5). Bankfull stage is $37 \mathrm{ft}$ on the Hickman gage. Stages for flows above bankfull discharge (e.g., 1,300,000 cfs) have been relatively stable during the entire period of record. Similarly, stages for flows at or below bankfull elevation remained relatively stable through approximately the mid-1990s though they exhibited some fluctuation. However, a decreasing trend appears to have begun during the late-1990s for these flows. 
Figure 5.5. Specific gage record at Hickman, KY (RM 922 AHP on the LMR).

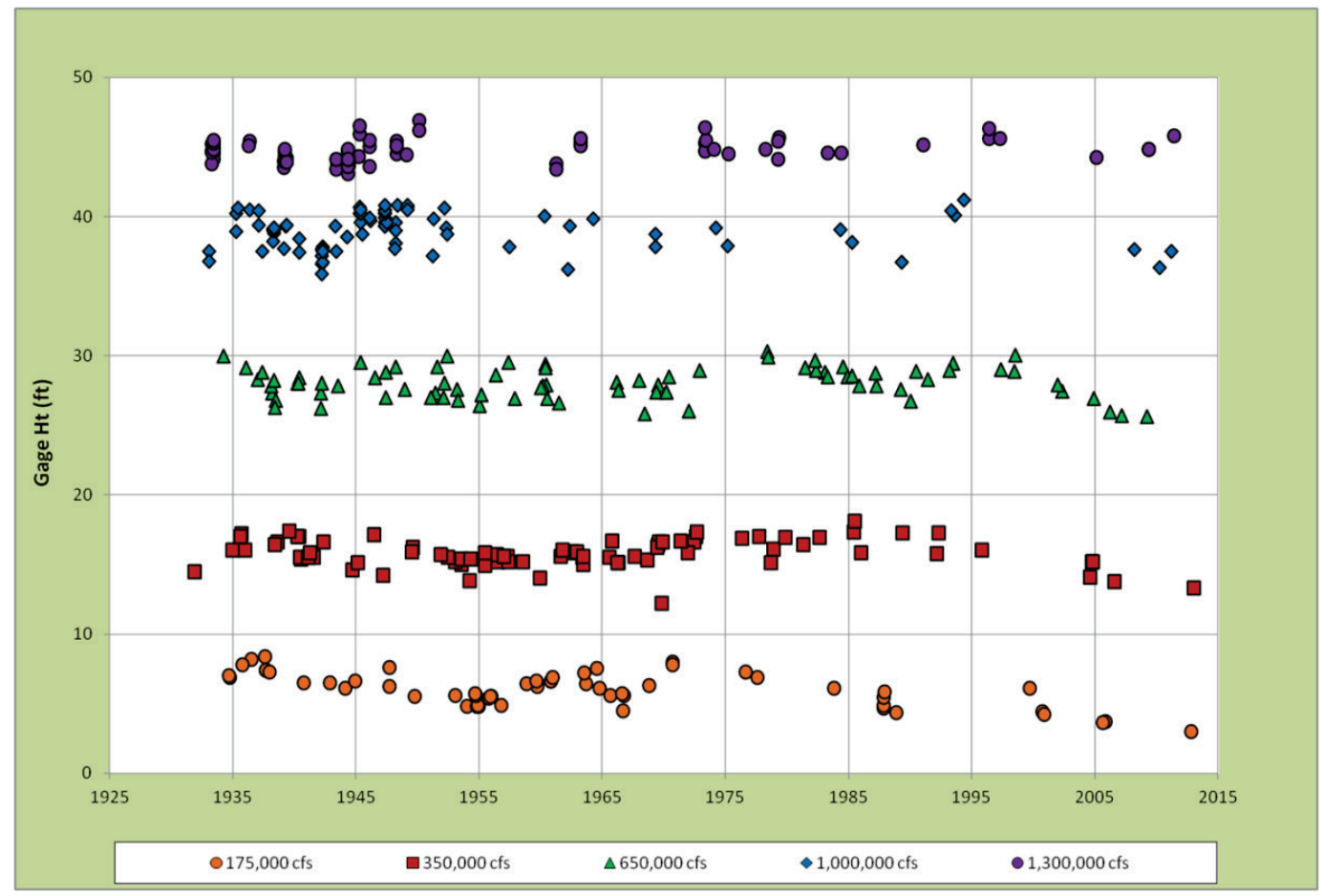

\subsubsection{Tiptonville gage}

Tiptonville is a secondary station located at RM 872.4 AHP on the LMR, for which discharge data are taken from the Hickman station, with a 1-day time lag. The period of record for the specific gage analysis extends from 1930 to 2013 (Figure 5.6). Bankfull stage is $37 \mathrm{ft}$ on the Tiptonville gage. The stages for overbank flows (e.g., 1,300,000 cfs) have been relatively stable during the period of record. Stages for mid-range flows $(650,000 \mathrm{cfs}$ and $1,000,000 \mathrm{cfs}$ ) were also relatively stable between the early-1930s until the mid- to late-1990s after which there has been a slight, decreasing trend. Stages for lower flows (175,000 cfs and 350,000 cfs) increased slightly from the early-1930s through to the 1960s and early-1970s. However, for these low discharges, a decreasing trend started in the early- to mid-1980s. Since the mid-1980s, the trend for stages to lower has been more pronounced for these lower flows than was the case for the higher flows. 
Figure 5.6. Specific gage record at Tiptonville, TN (RM 872.4 AHP on the LMR).

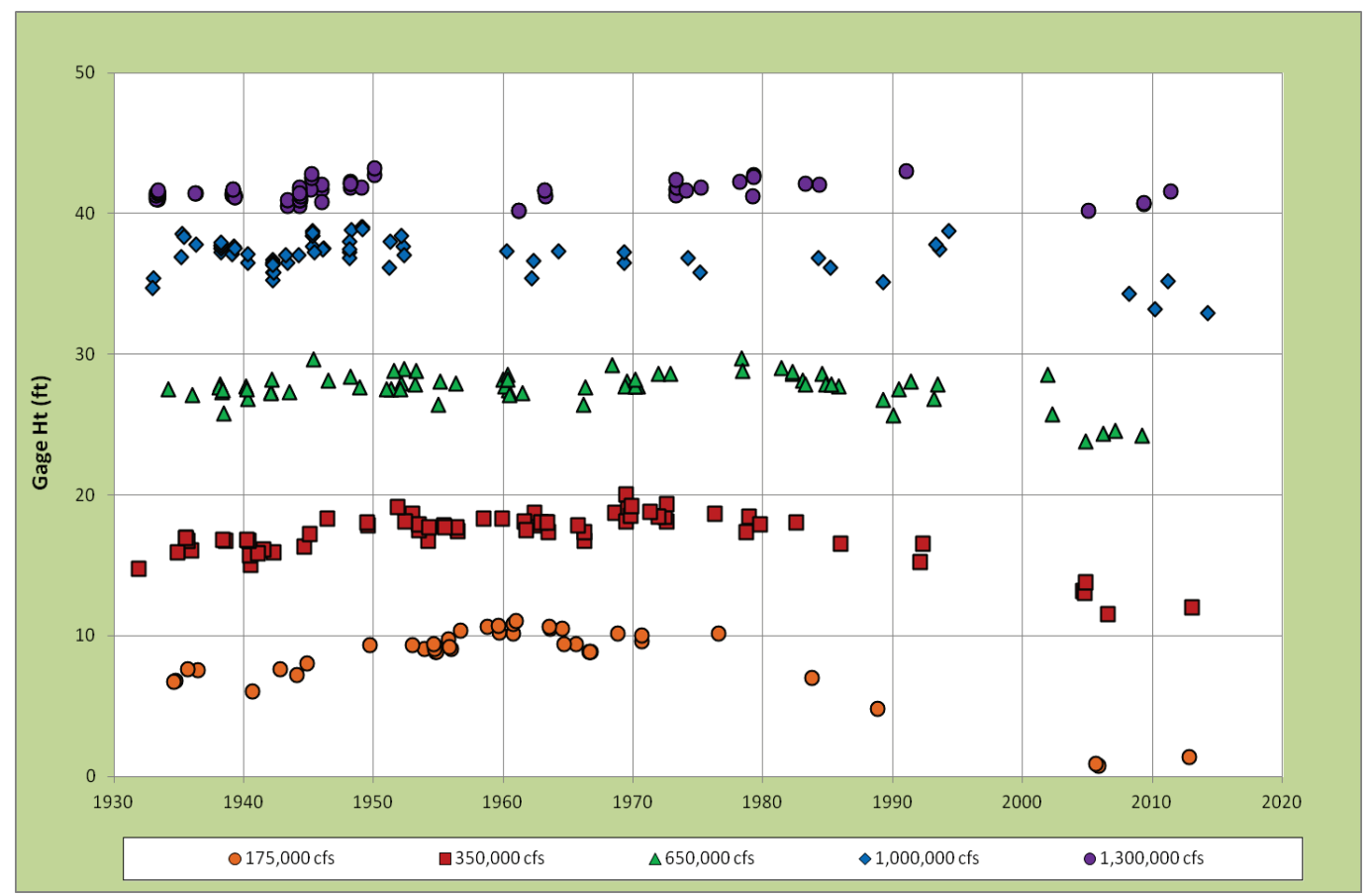

\subsubsection{Caruthersville gage}

Caruthersville is a secondary station located at RM 844.4 AHP on the LMR. Daily stages observed at Caruthersville were combined with discharges measured at Hickman, using a 1-day time lag. The period of record for the specific gage analysis extends from 1930 and 2013 (Figure 5.7). Bankfull stage is $35 \mathrm{ft}$ on the Caruthersville gage. Stages for overbank flows $(1,300,000 \mathrm{cfs})$ have been relatively stable throughout the period of record. Stages for lower flows display cyclic fluctuations through the mid- to late1980 s, with no definitive increasing or decreasing trend. However, since the 1990s, there appears to have been a slight decrease in stages for lower flows.

\subsubsection{Osceola gage}

Osceola is a secondary station located at RM 783.5 AHP on the LMR. Stages observed at Osceola are combined with discharges measured at Memphis (using a 1-day time lag) to produce the specific gage record. The period of record for the specific gage analysis extends from 1930 to 2013 (Figure 5.8). Bankfull stage at Osceola is $28 \mathrm{ft}$. Stages for all flows show a decreasing trend that persists between the 1930 s and the early- to mid1980 s. From the mid-1980s to present day, the stages for the high flows have been relatively stable. Stages for lower flows $(175,000 \mathrm{cfs}$ and $350,000 \mathrm{cfs}$ ) appear to have followed a decreasing trend throughout the period of record. 
Figure 5.7. Specific gage record at Caruthersville, TN (RM 844.4 AHP on the LMR).

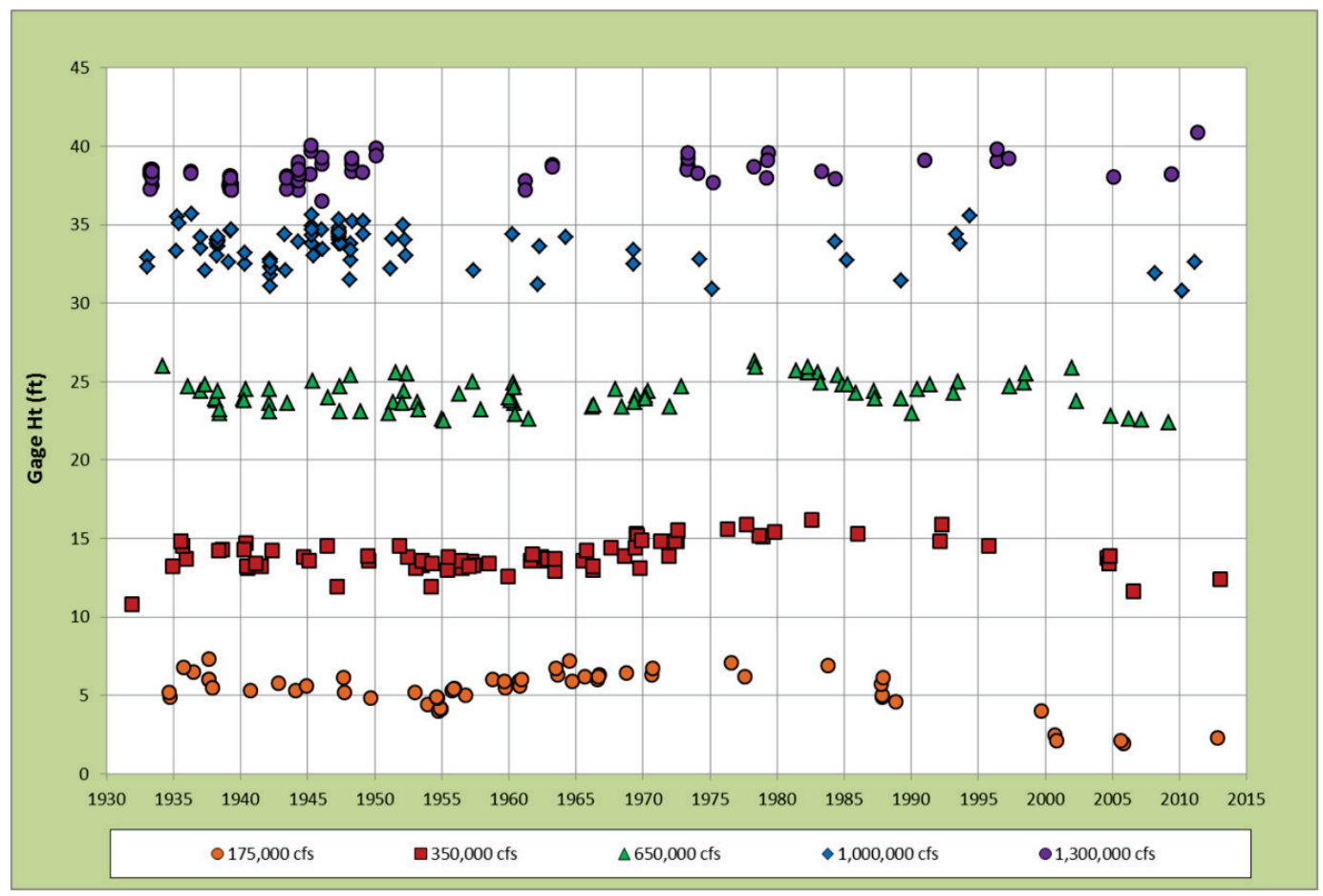

Figure 5.8. Specific gage record at Osceola, TN (RM 783.5 AHP on the LMR).

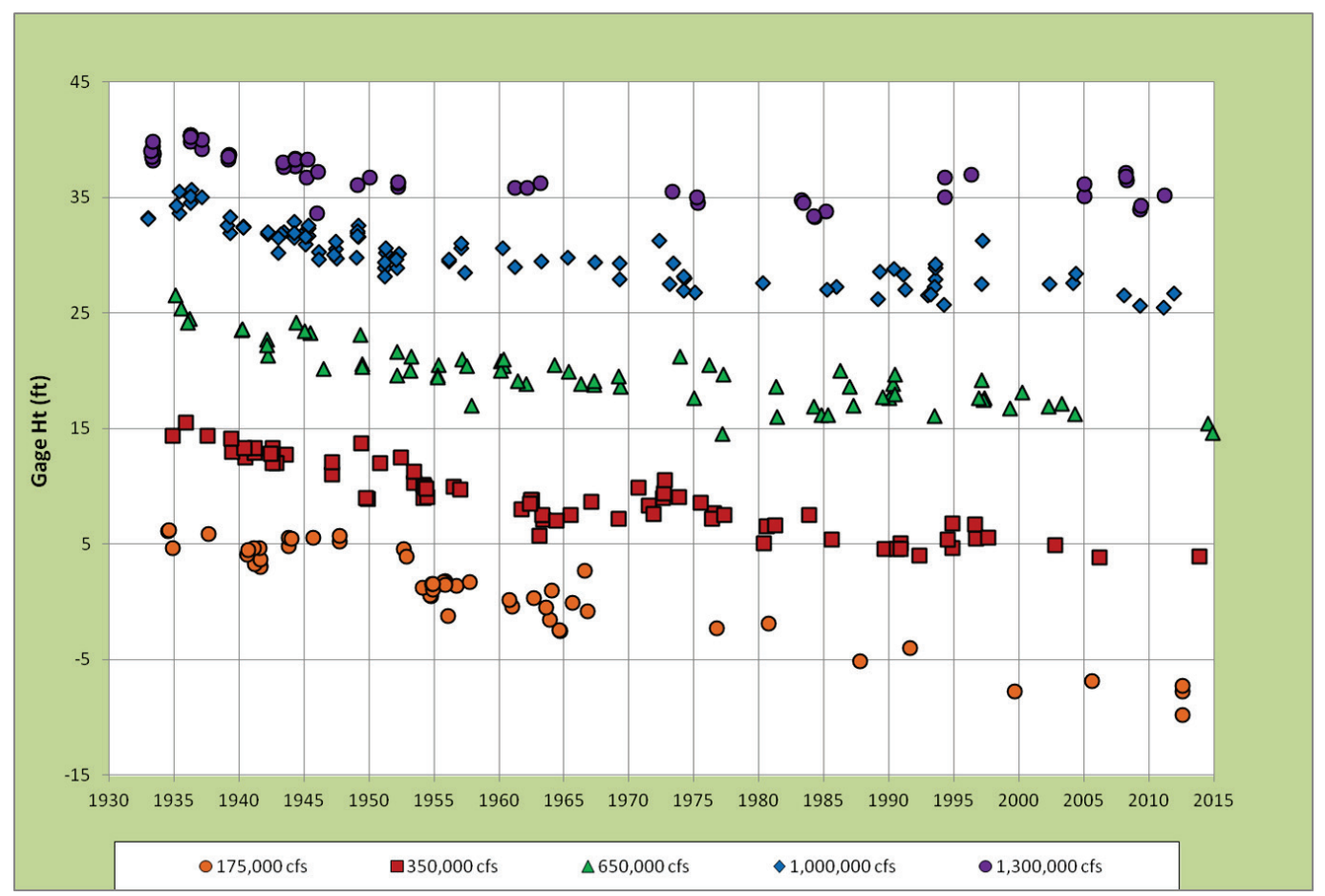




\subsubsection{Fulton gage}

Fulton is a secondary station located at RM 778.2 AHP on the LMR. Daily stages observed at Fulton were combined with discharges measured at Memphis (using a 1-day time lag) to produce the specific gage record. The period of record for the specific gage analysis extends from 1930 to 1990 (Figure 5.9). Bankfull stage is $34 \mathrm{ft}$ on the Fulton gage. As shown in Figure 5.9, there is a general decreasing stage trend in stages for all flows that persists from the 1930 s through the early- to mid- or late-1980s.

Figure 5.9. Specific gage record at Fulton, TN (RM 778.2 AHP on the LMR).

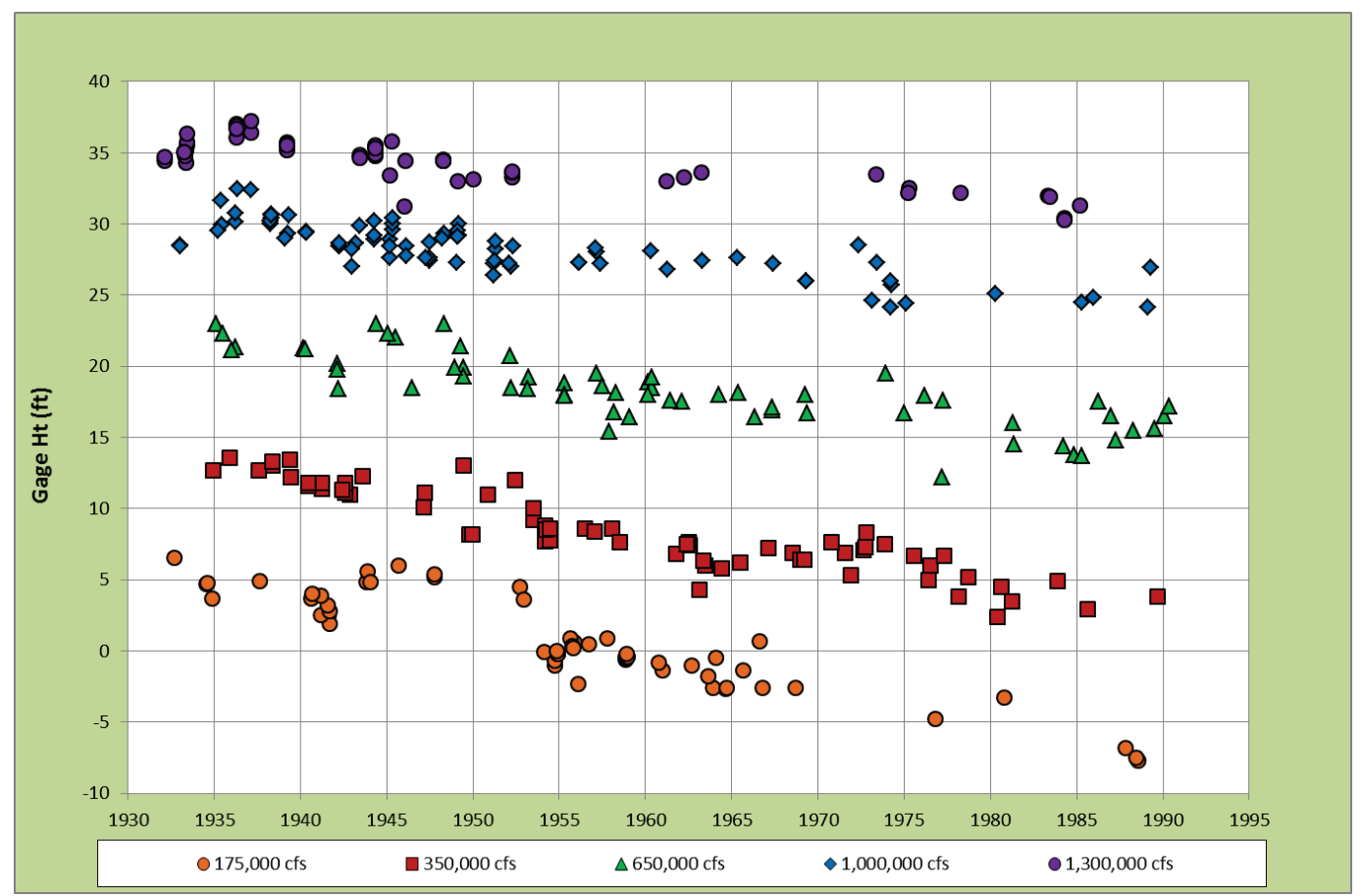

\subsubsection{Memphis gage}

Memphis is a primary station located at RM 734.7 AHP on the LMR. The period of record for the specific gage analysis extends from 1882 to 2014 (Figure 5.10), although there are only a few measurements in the 1880 s. Bankfull stage is $34 \mathrm{ft}$ on the Memphis gage. Stages for all flows display a decreasing trend that persists until the mid-1990s when stages increase abruptly. Stages resume their decreasing trend in the late-1990s.

Throughout the period of record, decreasing trends for lower flow stages are more pronounced than those for higher flows. 
Figure 5.10. Specific gage record at Memphis, TN (RM 734.7 AHP on the LMR).

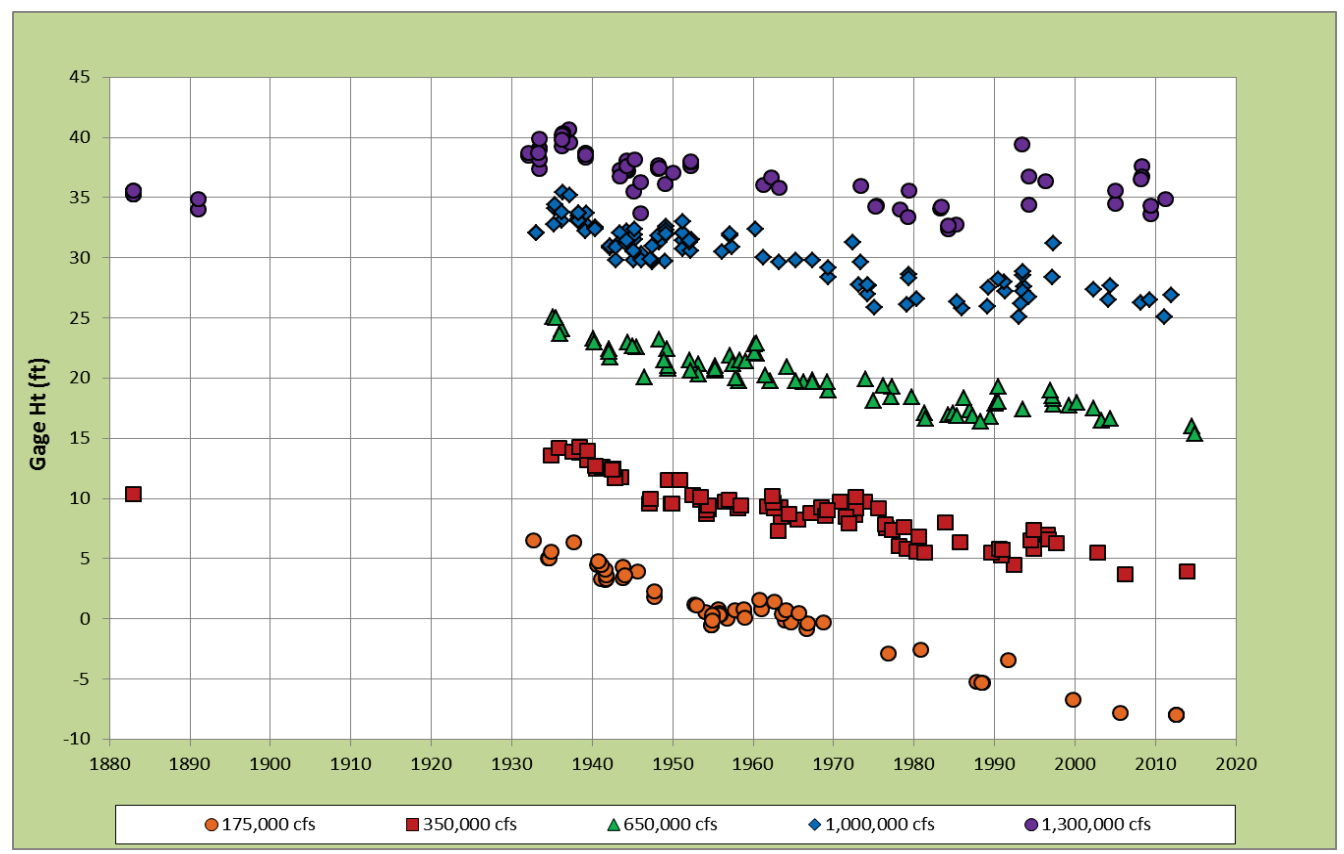

\subsubsection{Star Landing}

Star Landing is a secondary station located at RM 707.2 AHP on the LMR. Daily stages at Star Landing were combined with discharges measured at Memphis (using a 1-day time lag) to produce the specific gage record. The period of record for the specific gage analysis extends from 1930 to 1991 (Figure 5.11). Stage for all flows decreased from the mid- to late-1930s until the late-1940s to early-1950s. Stages then remained relatively stable until the mid-1980s. Some decrease in stages can be discerned since 1985, but confidence that this trend is real is low due to the limited number of data points available during this period of the record.

\subsubsection{Mhoon Landing gage}

Mhoon Landing is a secondary station located at RM 687.5 AHP on the LMR. Stages observed at Mhoon Landing were combined with discharges measured at Memphis (using a 1-day time lag) to produce the specific gage record. The period of record for the specific gage analysis extends from 1930 to 1981 (Figure 5.12). Bankfull stage is $35 \mathrm{ft}$ on the Mhoon Landing gage. As shown in Figure 5.12, a clear, decreasing trend in stages for all flows began abruptly during the early-1940s, persisting throughout the 1940 and into the early-1950s. Since then, stages have remained relatively stable. That said, there appears to have been a slight, decreasing trend in stages for the lower flows (e.g., 650,000 cfs and smaller) since the 1970s, though the limited data preclude establishing this with confidence. 
Figure 5.11. Specific gage record at Star Landing, MS (RM 707.2 AHP on the LMR).

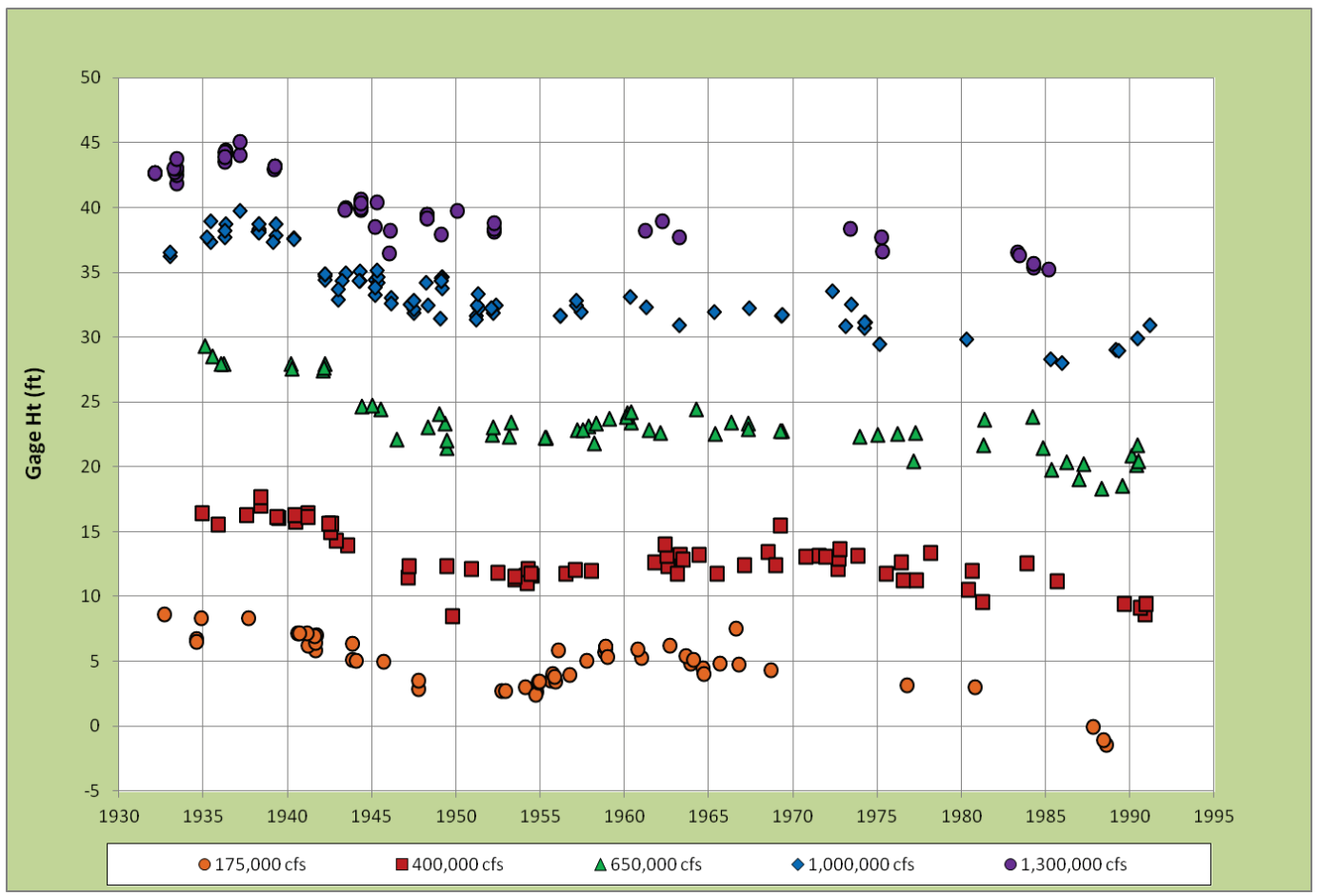

Figure 5.12. Specific gage record at Mhoon Landing, MS (RM 687.5 AHP on the LMR).

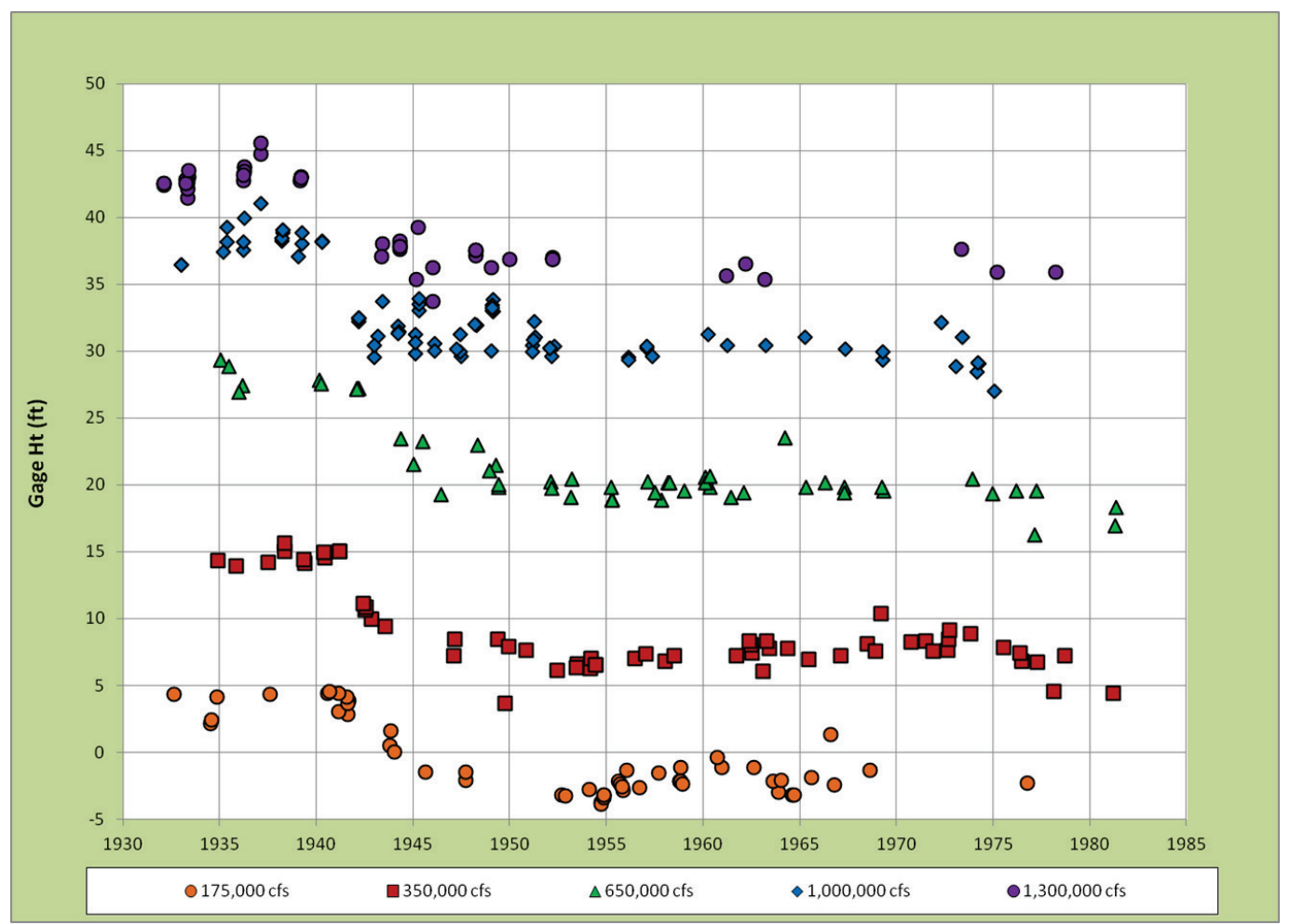




\subsubsection{Helena gage}

Helena is a primary station located at RM 663 AHP on the LMR. The period of record for the specific gage analysis extends from 1882 to 2014 (Figure 5.13). Bankfull stage is $41 \mathrm{ft}$ on the Helena gage. Although data are limited prior to the 1930 s, there appears to have been a slight, increasing trend in stages between the early-1880s the early-1900s. Between the 1930 and 2014, a generally decreasing trend, with some cyclic, fluctuations superimposed on it, can be discerned in the stages for all flows. The decreasing trend in stages is strongest for lower flows and is much less obvious for higher flows.

Figure 5.13. Specific gage record at Helena, AR (RM 663 AHP on the LMR).

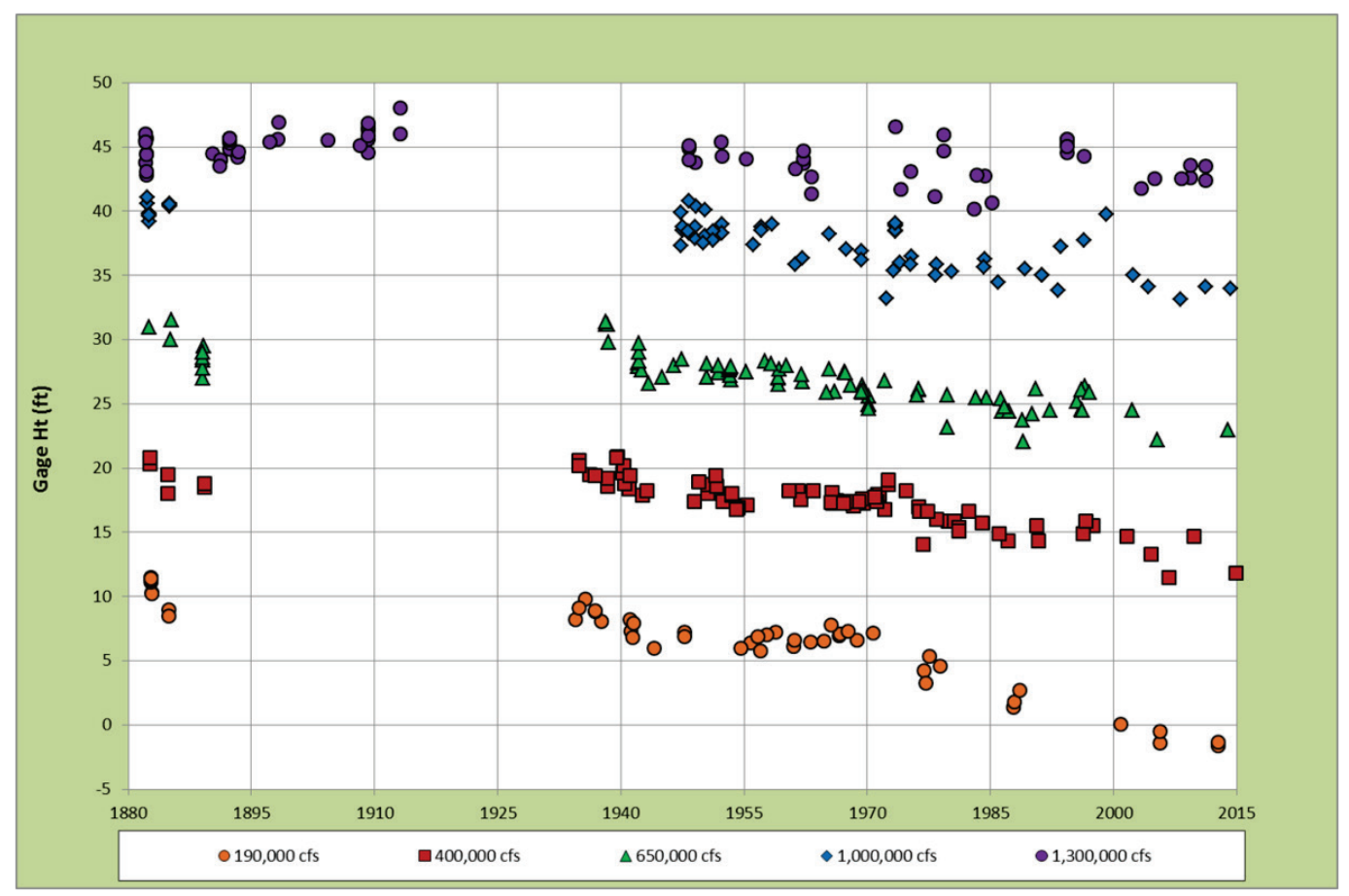

\subsubsection{Fair Landing gage}

Fair Landing is a secondary station located at RM 632.5 AHP on the LMR. Stages observed at Fair Landing were combined with discharges measured at Helena to produce the specific gage record. The period of record for the specific gage analysis extends from 1934 to 2001 (Figure 5.14). Bankfull stage is $40 \mathrm{ft}$ on the Fair Landing gage. Since the late-1940s, stages for higher flows $(1,000,000 \mathrm{cfs}$ and 1,300,000 $\mathrm{cfs})$ have fluctuated cyclically while remaining relatively stable. Stages for mid-range and lower flows (650,000 cfs and smaller) display an abrupt decrease in the early-1940s that persists through the late-1940s and into the early-1950s. Stages were 
then relatively stable until the mid-1970s when they again began to decrease. Since the early-1980s, stages have been relatively stable with the exception of those for $190,000 \mathrm{cfs}$, which may have lowered somewhat during the late-1980s.

Figure 5.14. Specific gage record at Fair Landing, AR (RM 632.5 AHP on the LMR).

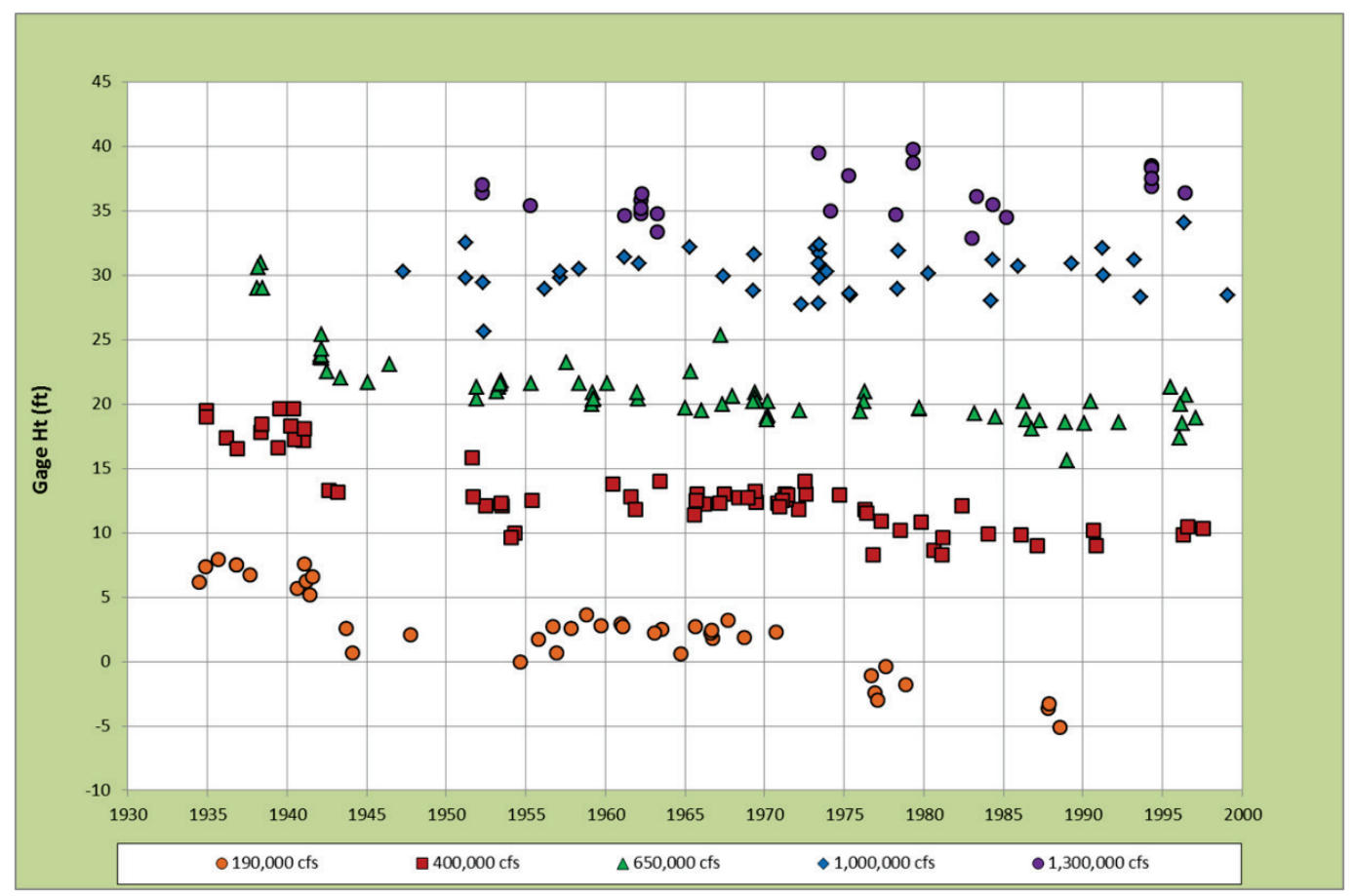

\subsubsection{Rosedale gage}

Rosedale is a secondary station located at RM 592.2 AHP on the LMR. Daily stages observed at Rosedale were coupled with measured discharges from Helena (using a 1-day time lag) to produce the specific gage record. The period of record for the specific gage analysis extends from 1940 to 2014 (Figure 5.15). Bankfull stage is $44 \mathrm{ft}$ at Rosedale. Stages for higher flows (e.g., 1,300,000 cfs) have fluctuated while overall remaining relatively stable from the mid-1940s through to 2014. Stages for mid-range and lower flows (1,000,000 cfs and smaller) show a generally decreasing trend throughout the period of record upon which cyclic fluctuations are superimposed. These decreasing trends are much more pronounced for stages associated with lower flows compared to those for higher flows. 
Figure 5.15. Specific gage record at Rosedale, MS (RM 592.2 AHP on the LMR).

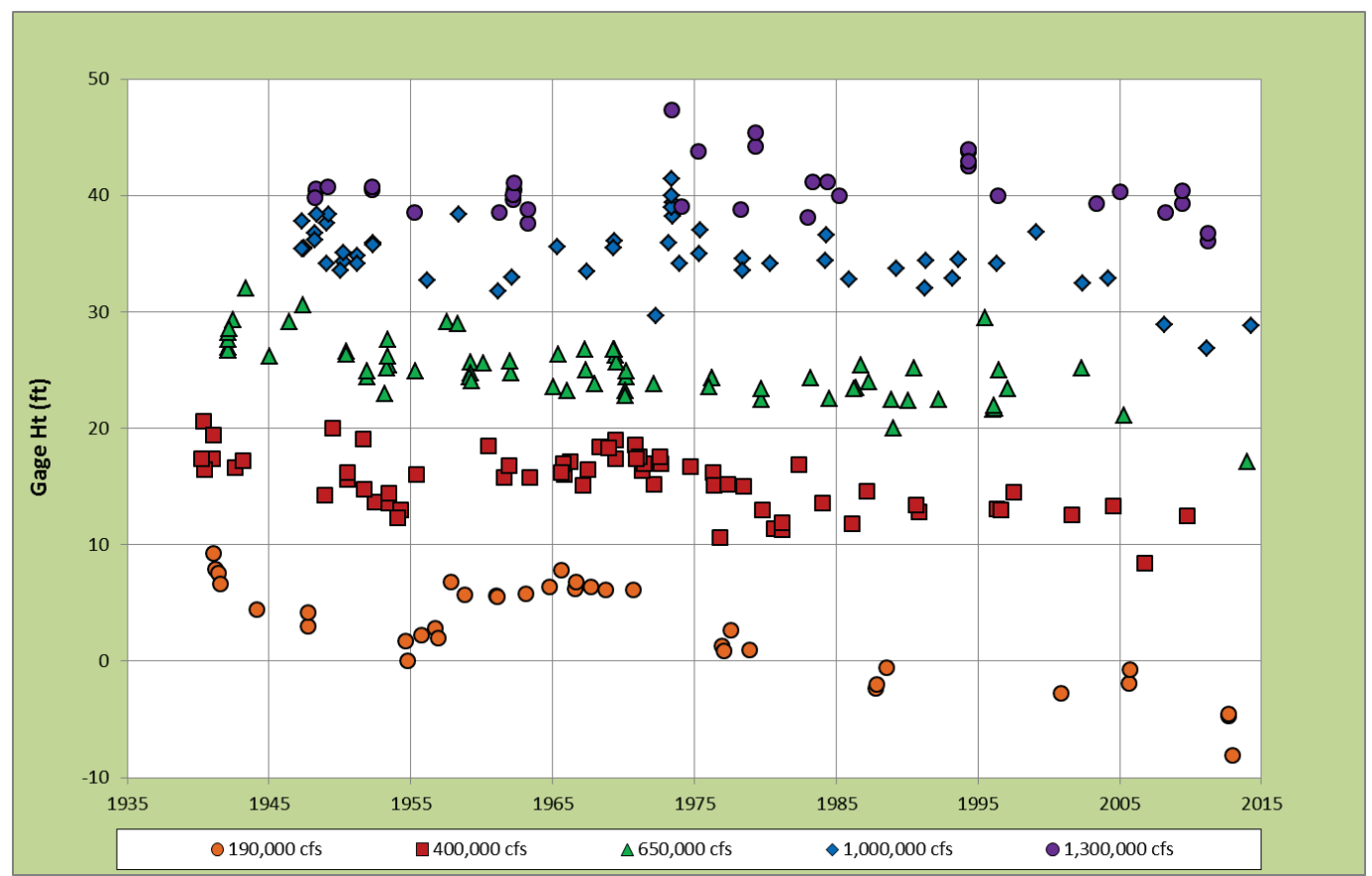

\subsubsection{Arkansas City gage}

Arkansas City is a primary station located at RM 554.1 AHP on the LMR. The period of record for the specific gage analysis extends from 1884 to 2014 (Figure 5.16). Bankfull stage is $44 \mathrm{ft}$ on the Arkansas City gage. Highflow stages $(1,400,000 \mathrm{cfs})$ clearly increased between the early-1880 and early-1930s. Similar stage increases are also apparent for lower flows although data scarcity reduces confidence in this statement. An abrupt drop in stages occurred between the early-1930s and the mid- to late1940 with stage reductions being greatest for high flows. Since the early1950s, stages for flows greater than 200,000 cfs appear to have been relatively stable though a slight increasing trend for 1,500,000 cfs and a slight decreasing trend for 400,000 cfs can be discerned. For a discharge of 200,000 cfs, a generally decreasing trend in stages has persisted since the early-1950s. 
Figure 5.16. Specific gage record at Arkansas City, AR (RM 554.1 AHP on the LMR).

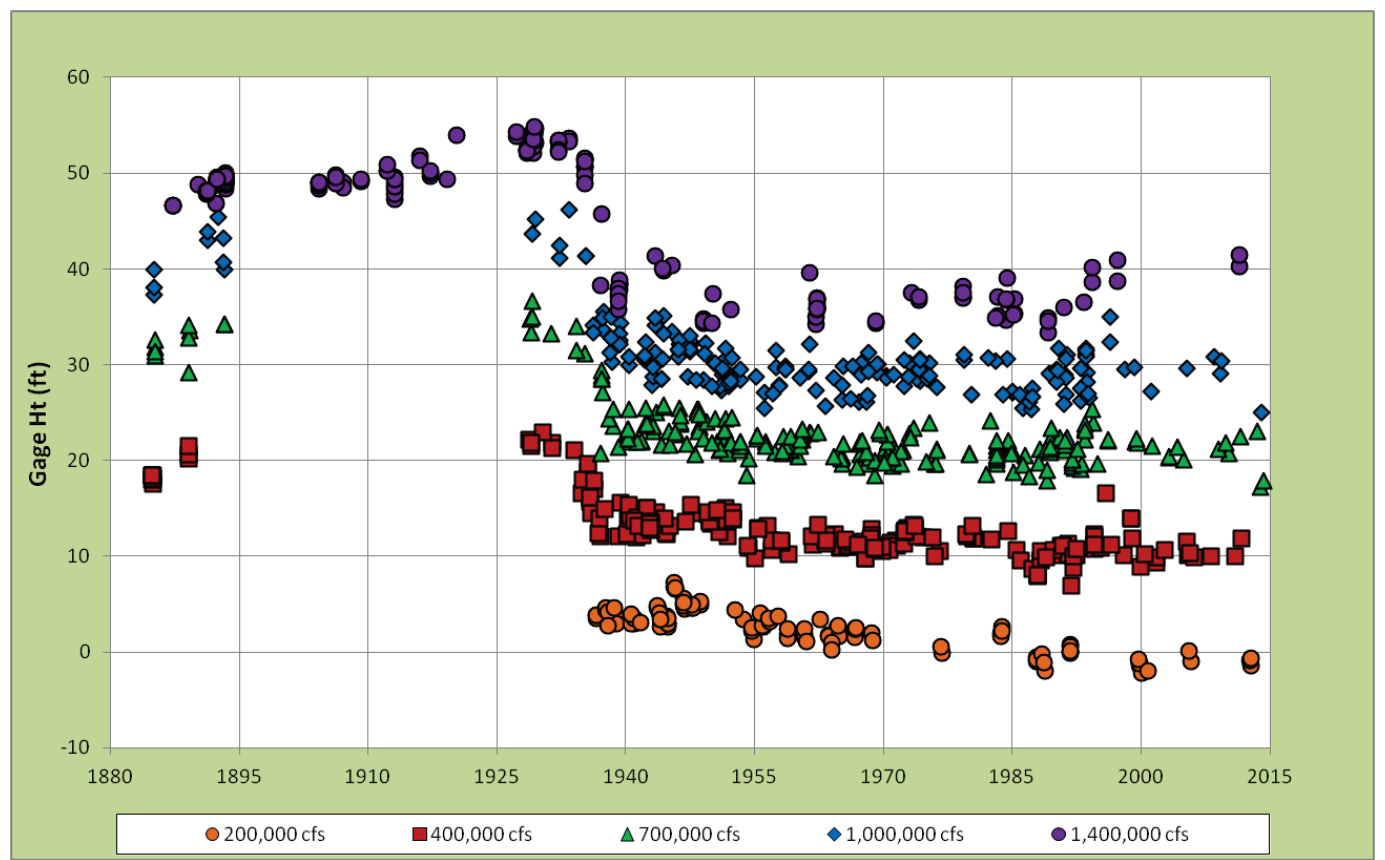

\subsubsection{Greenville gage}

Greenville is a secondary station located at RM 531.5 AHP on the LMR. Daily stages observed at Greenville were combined with discharges measured at Arkansas City (with no time lag being necessary) to produce the specific gage record. The period of record for the specific gage analysis extends from 1941 to 2014 (Figure 5.17). Bankfull stage is $48 \mathrm{ft}$ on the Greenville gage. Stages for mid-range and higher flows (greater than $200,000 \mathrm{cfs}$ ) have been relatively stable thoughout the period of record with the exception of a slight, increasing trend since 1990 for a high flow of $1,400,000 \mathrm{cfs}$. Stages for the lower flow of $200,000 \mathrm{cfs}$ have fluctuated but appear to display an overall, decreasing trend throughout the period of record. 
Figure 5.17. Specific gage record at Greenville, MS (RM 531.5 AHP on the LMR).

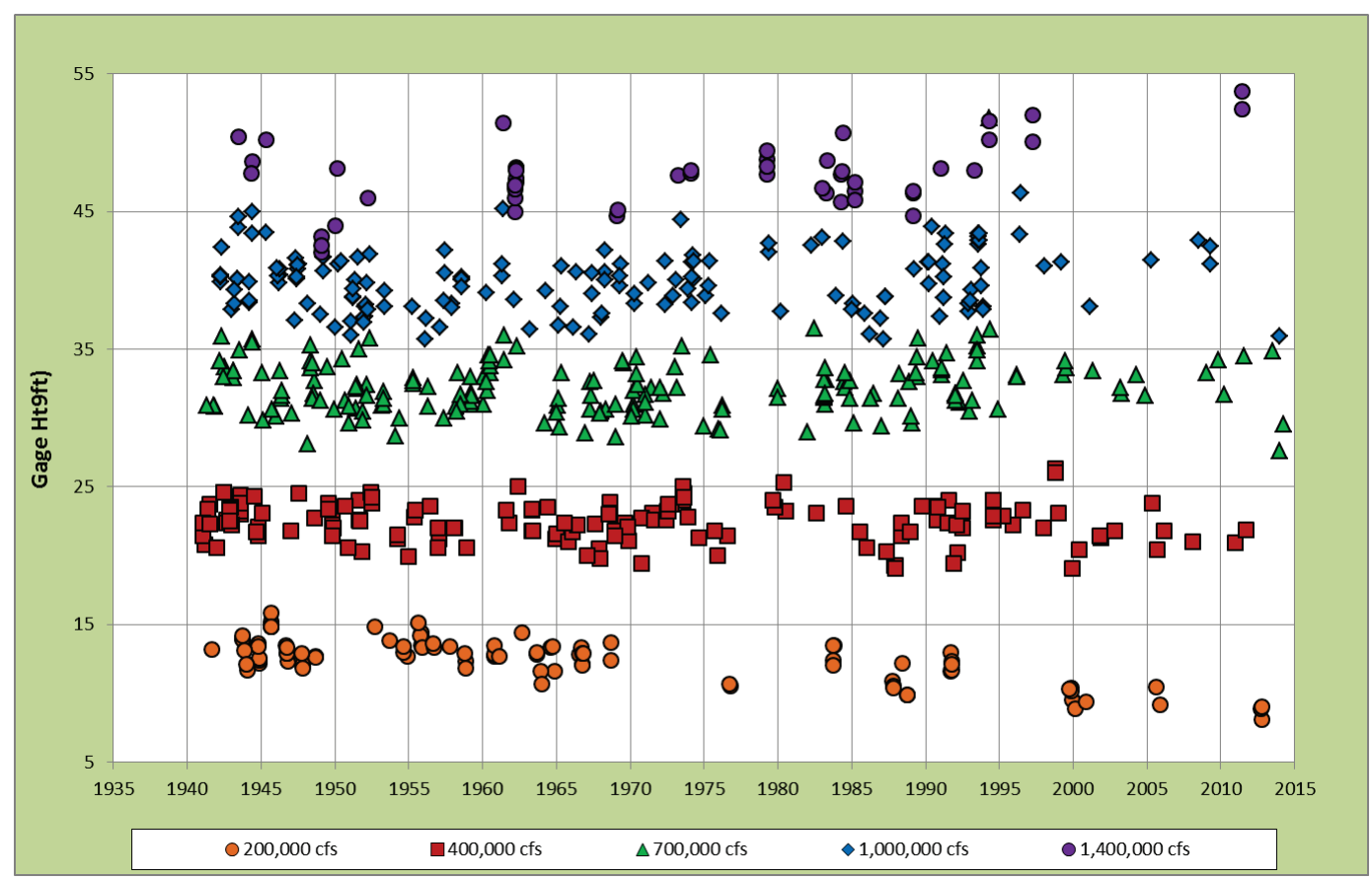

\subsubsection{Lake Providence gage}

Lake Providence is a secondary station located at RM 487.2 AHP on the LMR. Observed stages at Lake Providence were combined with discharges measured at Vicksburg (using a 1-day time lag) to generate the specific gage record. The period of record for the specific gage analysis extends from 1906 to 2014 (Figure 5.18). Bankfull stage is $37 \mathrm{ft}$ on the Lake Providence gage. From the early-1900s through the late-1920s, a generally increasing stage trend is apparent in stages for high flows $(1,500,000 \mathrm{cfs})$. However, in the early-1930s, there was a fairly abrupt decrease in stages for all flows that persisted through the late-1940s and into the early-1950s. Since the 1950s, the stages have fluctuated somewhat while remaining relatively stable, overall. 
Figure 5.18. Specific gage record at Lake Providence, LA (RM 487.2 AHP on the LMR).

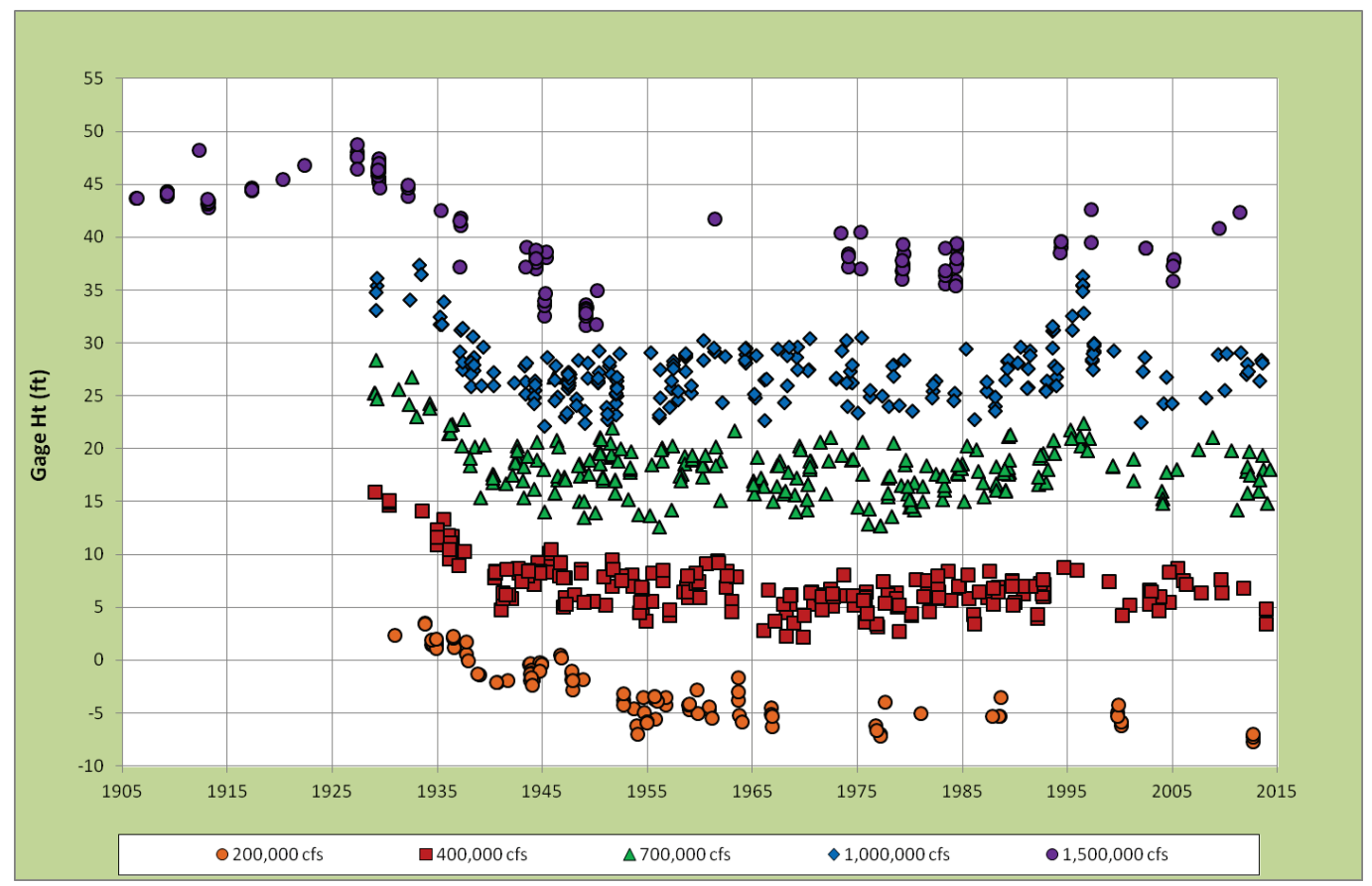

\subsubsection{Vicksburg gage}

Vicksburg is a primary station located at RM 435.7 AHP on the LMR. The period of record for the specific gage analysis extends from 1858 to 2014 (Figure 5.19), although data for the nineteenth and early twentieth centuries are sparse. Bankfull stage is $43 \mathrm{ft}$ on the Vicksburg gage. If the few data collected prior to the 1930 can be relied upon, an increasing trend can be discerned in stages during that period, particularly for the highest flow (1,500,000 cfs). An abrupt decrease in stages for all flows occurred during the early-1930s, and a decreasing trend continued throughout the 1940s and early-1950s. Since then, stages for all flows greater than 200,000 cfs have fluctuated around what appears to be a generally increasing trend. In contrast, stages for a discharge of 200,000 cfs have been relatively stable since the 1950 . 
Figure 5.19. Specific gage record at Vicksburg, MS (RM 435.7 AHP on the LMR).

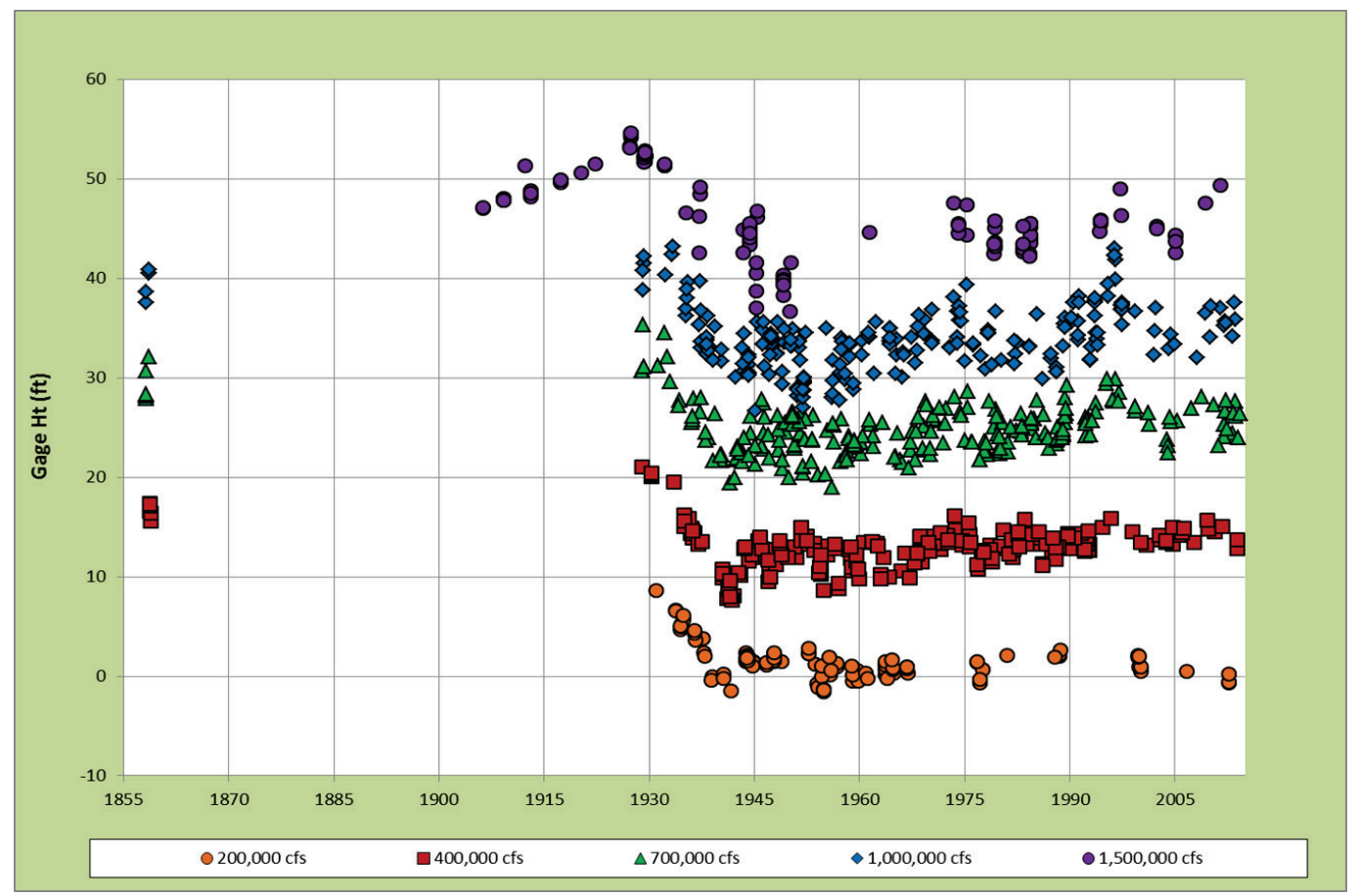

\subsubsection{St. Joseph gage}

St. Joseph is a secondary station located at RM 396.4 AHP on the LMR. The specific gage record was developed by coupling daily stages observed at St. Joseph with discharges measured at Natchez using a 1-day time lag. The period of record for the specific gage analysis extends from 1935 to 1996 (Figure 5.20). Bankfull stage is $40 \mathrm{ft}$ on the St. Joseph gage. As shown in Figure 5.20, a decreasing trend in stages began in the mid-1930 and persisted into the early-1940s. Between the mid-1940s and the end of the period of record in the mid-1990s, stages for all but the lowest discharge increased. Stages for 200,000 cfs remained relatively stable.

\subsubsection{Natchez gage}

Natchez is a primary station located at RM 363.3 AHP on the LMR. The period of record for the specific gage analysis extends from 1890 to 2014 (Figure 5.21). Bankfull stage is $48 \mathrm{ft}$ on the Natchez gage. If the few observations made in the late nineteenth century are indicative, then stages may have been increasing prior to the 1930s, at least for a high discharge of 1,400,000 cfs. As shown in Figure 5.21, stages for all flows decreased abruptly in the late-1930s and continued to display a downward trend during the early-1940s. Since the mid-1940s, a general, increasing trend is evident in the stages associated with all selected flows. 
Figure 5.20. Specific gage record at St. Joseph, LA (RM 396.4 AHP on the LMR).

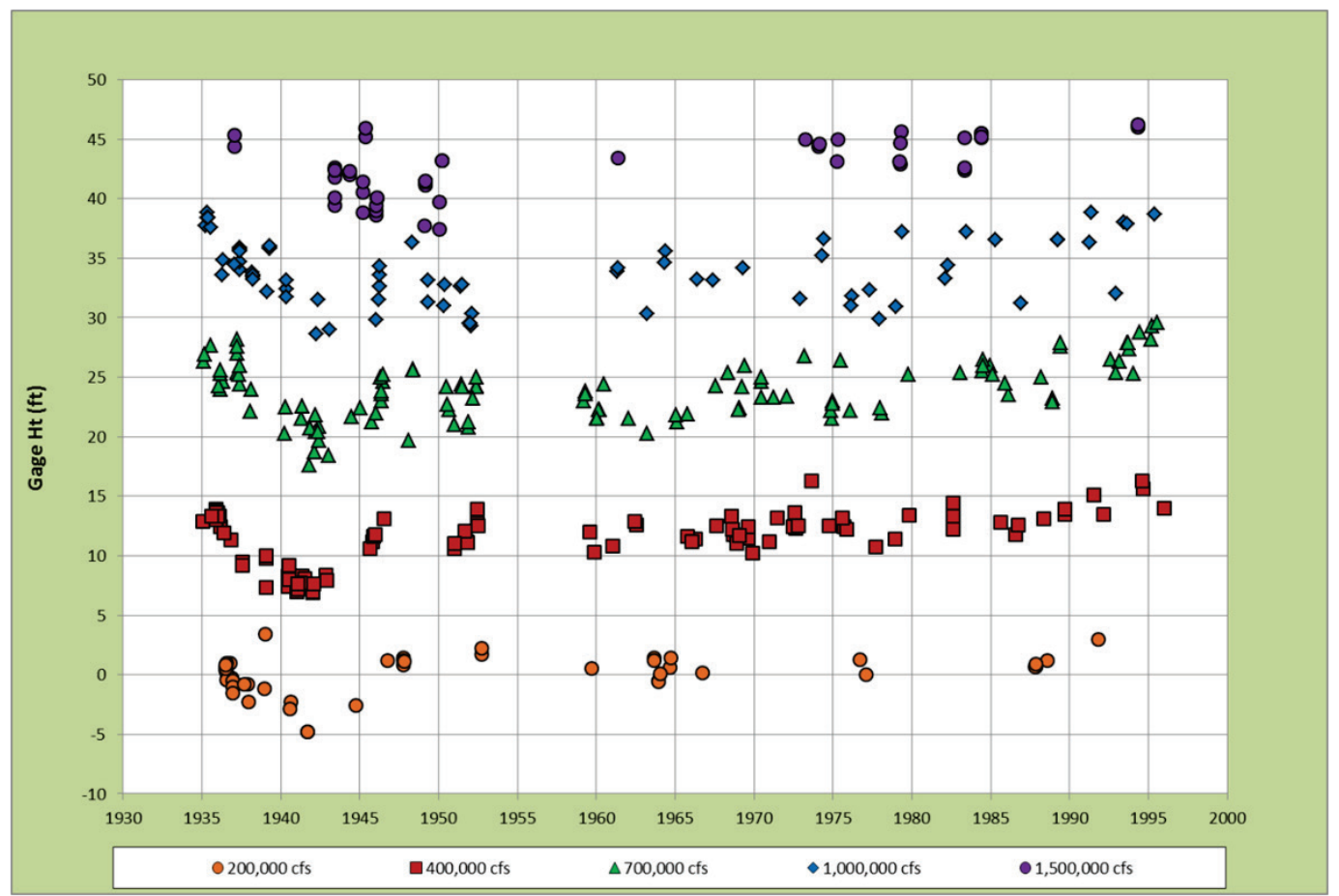

Figure 5.21. Specific gage record at Natchez, MS (RM 363.3 AHP on the LMR).

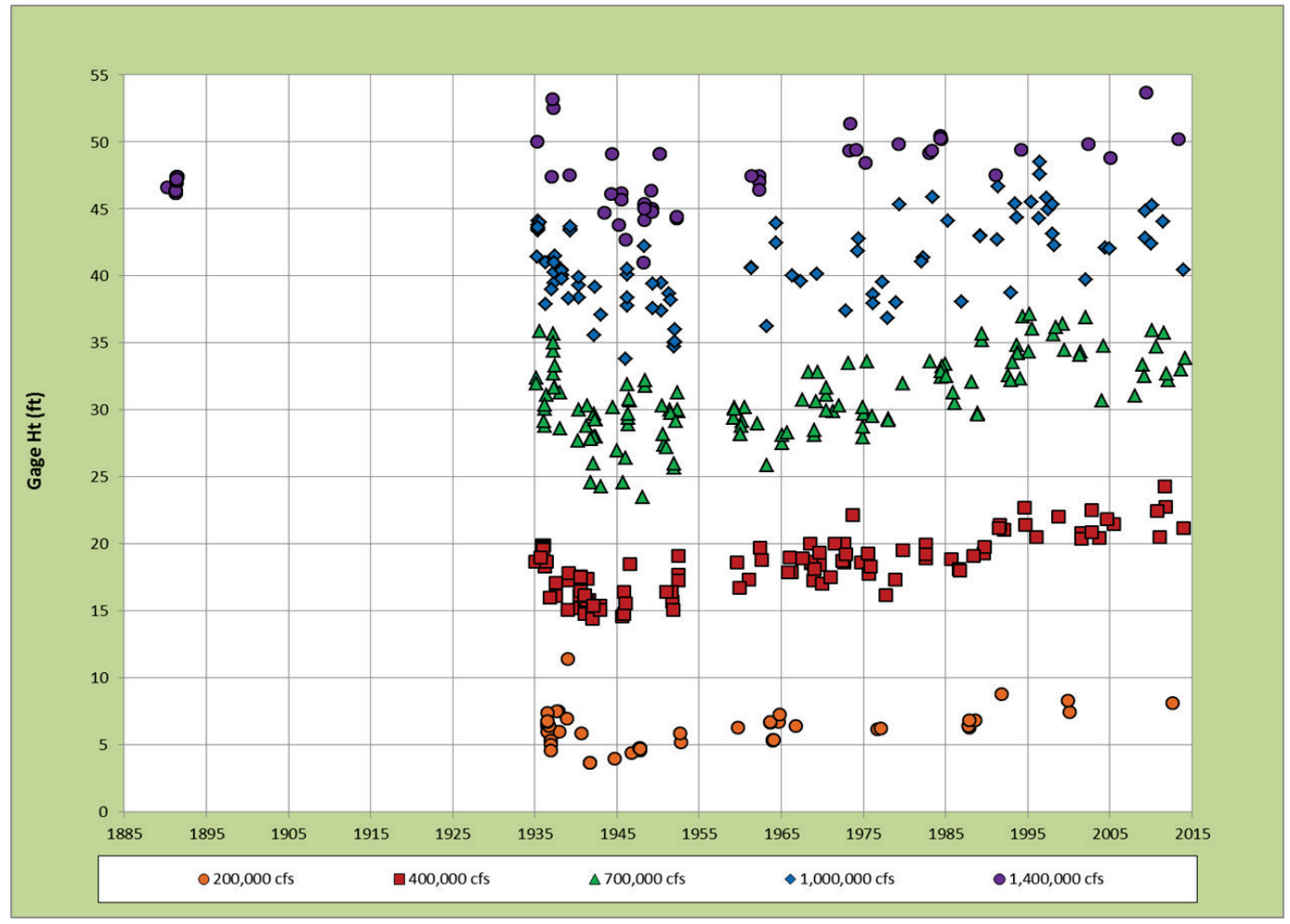




\subsubsection{Red River Landing gage}

Red River Landing is a primary station located at RM 302.4 AHP on the LMR. The discharge is measured at Tarbert Landing, located only 4 miles downstream at RM 306.2. The period of record for the specific gage analysis extends from 1943 to 2015 (Figure 5.22). Bankfull stage is $46 \mathrm{ft}$ on the Red River Landing gage. Between the early-1940s and early-1970s, stages for the higher flows (700,000 cfs and 1,000,000 cfs) were relatively stable while those for lower flows (200,000 cfs and 400,000 cfs) had a slightly increasing trend. As shown in Figure 5.22, there was an abrupt upward shift in stages during the mid- to early-1970s. Since then, stages for all flows have fluctuated somewhat while continuing to increase slightly.

Figure 5.22. Specific gage record at Red River Landing, LA (RM 302.4 AHP on the LMR).

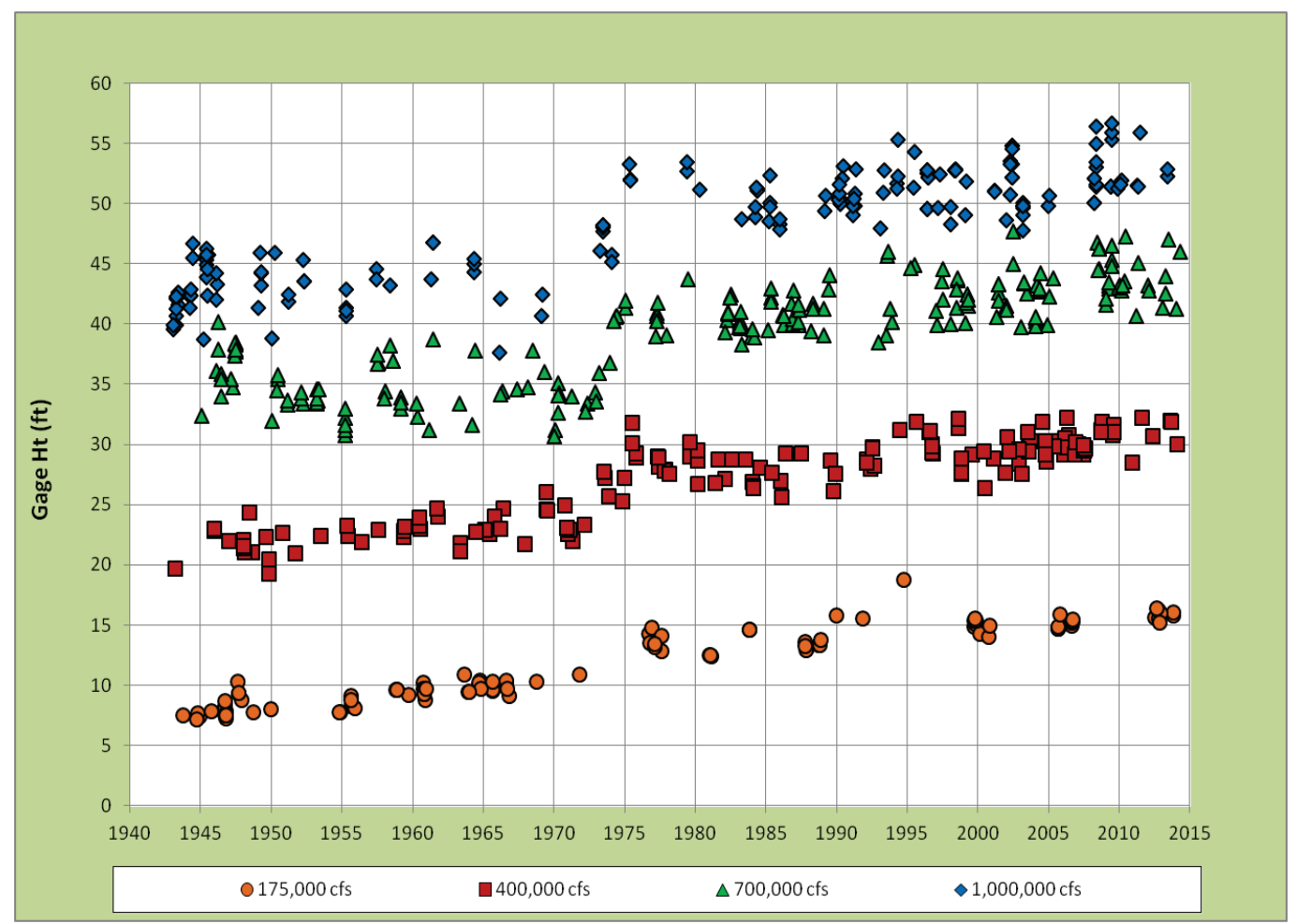

\subsubsection{Bayou Sara gage}

Bayou Sara is a secondary station located at RM 265.4 AHP on the LMR. The specific gage record was developed by coupling the daily stages at Bayou Sara with the discharges measured at Tarbert Landing. The period of record for the specific gage analysis extends from 1963 to 2015 (Figure 5.23). Bankfull stage is $36 \mathrm{ft}$ on the Bayou Sara gage. Stages appear to have increased slightly between the early-1960s and early-1970s, though confidence in this statement is limited due to lack of data during this 
period. During the mid-1970s, stages exhibit the same abrupt upward shift that is evident in the specific gage record just upstream at Red River Landing. Since the mid-1970s, stages have fluctuated while showing no consistent trend.

Figure 5.23. Specific gage record at Bayou Sara, LA (RM 265.4 AHP on the LMR).

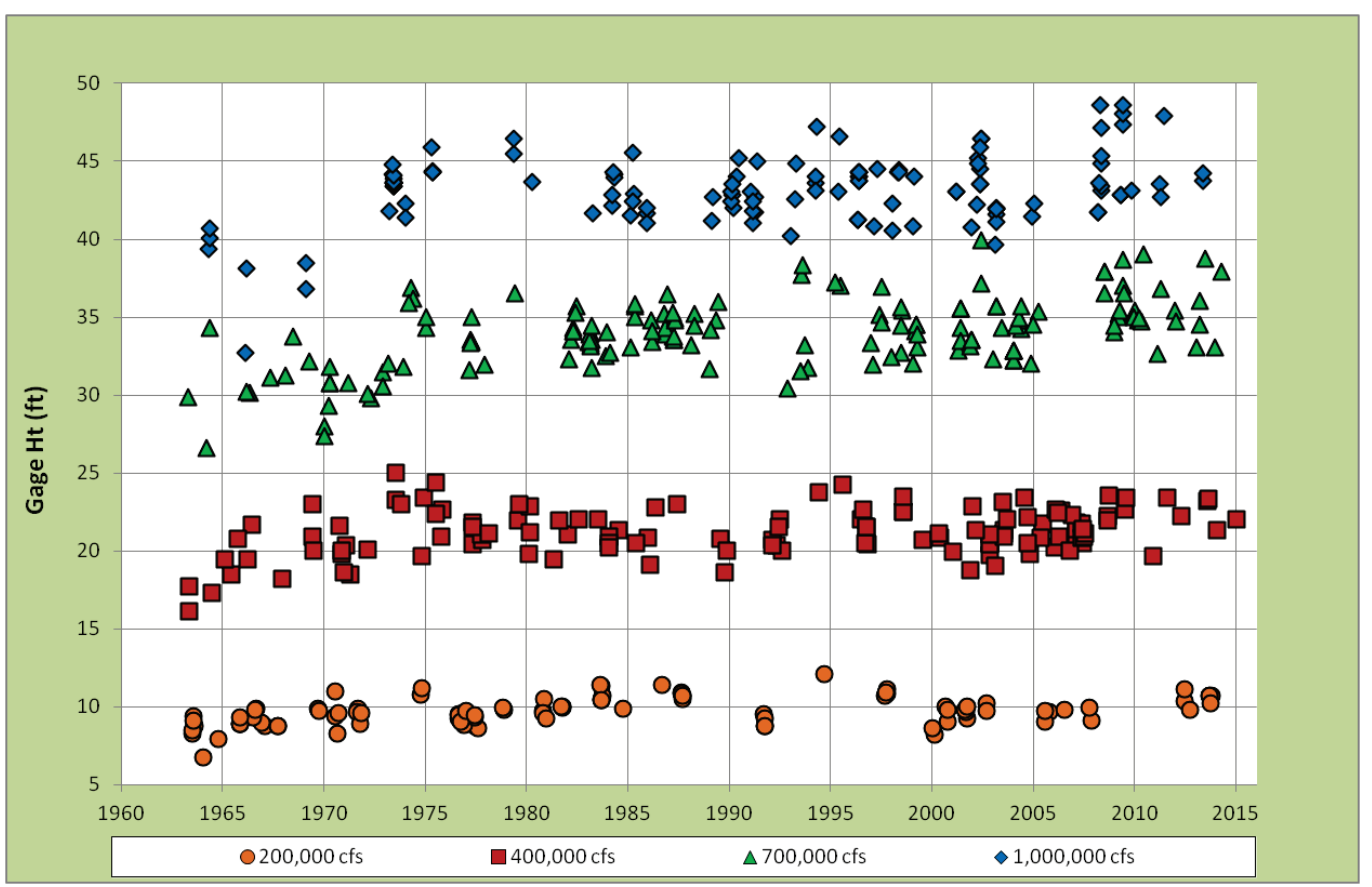

\subsubsection{Baton Rouge gage}

Baton Rouge is a secondary station located at RM 228.4 AHP on the LMR. The specific gage record was generated by coupling discharges measured at Tarbert Landing with observed daily stages at Baton Rouge using a 1day time lag. The period of record for the specific gage analysis extends from 1963 to 2015 (Figure 5.24). Bankfull stage is $29 \mathrm{ft}$ on the Baton Rouge gage. As is evident in Figure 5.24, the abrupt upward shift in stages during the early- to mid-1970s that occurred at Red River Landing and Bayou Sara (the two stations immediately upstream) is also present in the record for Baton Rouge. Since the mid-1970s, stages have been relatively stable, albeit there have been cyclic fluctuations. 
Figure 5.24. Specific gage record at Baton Rouge, LA (RM 228.4 AHP on the LMR).

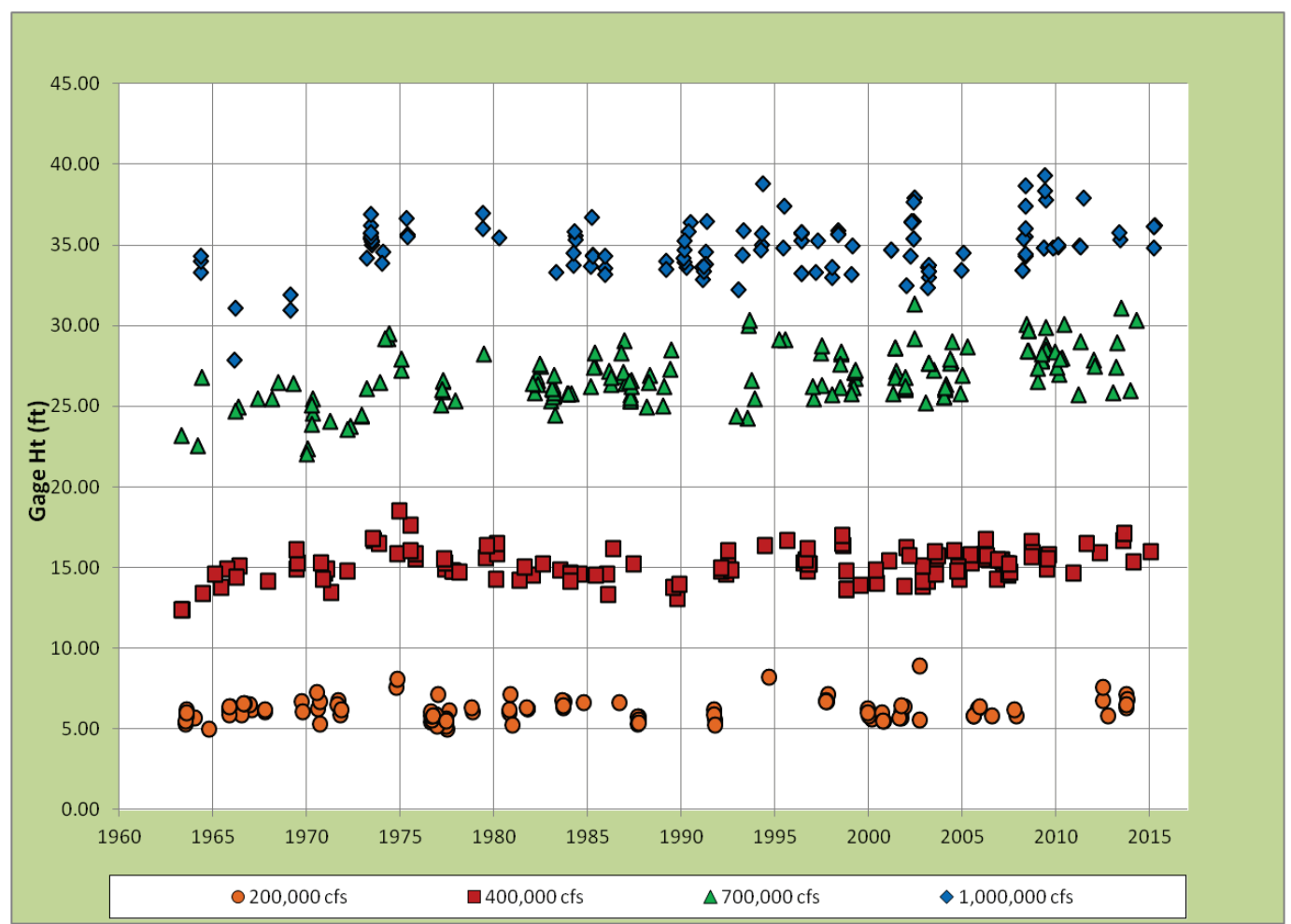

\subsubsection{Donaldsonville gage}

Donaldsonville is a secondary station located at RM 175.4 AHP on the LMR. The specific gage record was developed by combining daily stages observed at Donaldsonville with discharges measured at Tarbert Landing using a 1-day time lag. The period of record for the specific gage analysis extends from 1963 to 2015 (Figure 5.25). Bankfull stage is $23 \mathrm{ft}$ on the Donaldsonville gage. Similar to the three stations immediately upstream, the record shows an abrupt upward shift in stages during the early- to mid-1970s. However, stages for all discharges have fluctuated since then but appear to show a slight, decreasing trend that persisted until the early1990s. Since the 1990s, stages have been relatively stable. 
Figure 5.25. Specific gage record at Donaldsonville, LA (RM 175.4 AHP on the LMR).

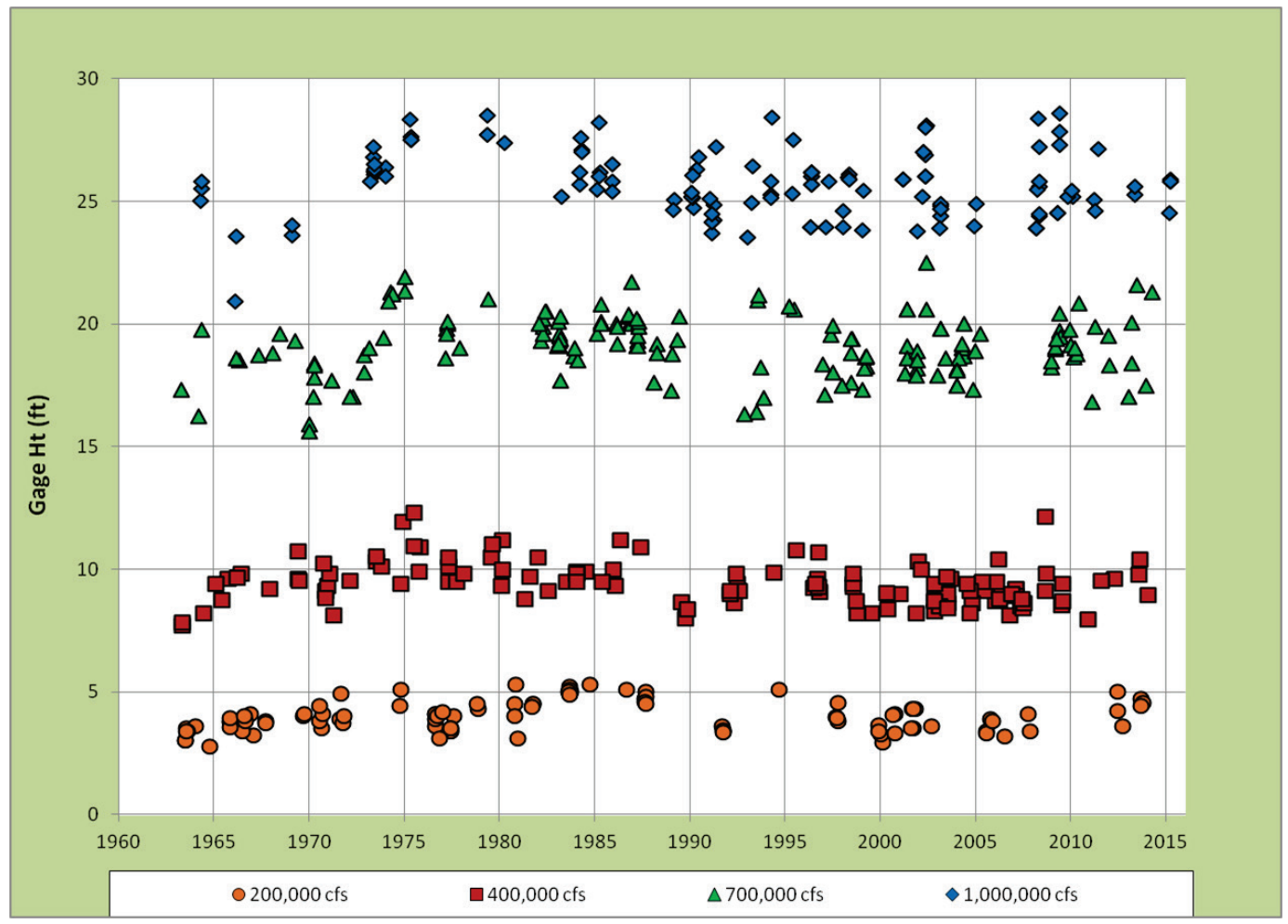




\section{Discussion}

For the purposes of this discussion, the Mississippi River is considered to consist of three distinctively different reaches:

1. the Middle Mississippi River (MMR), which includes the St. Louis, Chester, and Thebes stations

2. the upper course of the Lower Mississippi River (LMR), which includes all stations between Columbus and Natchez

3. the lower course of the LMR, which includes stations between Red River Landing and Donaldsonville.

The LMR was divided into an upper and lower course because of the diversion of over $20 \%$ of the flow through the Old River Control Complex. See previously presented Figure 4.1 (for station locations) and Table 4.1 (for station descriptions).

Although the response of the Mississippi River reflects an integration of many factors, the singular impacts of the meander cutoffs were so dramatic and far reaching that they are critical to properly assessing the long-term morphology of the river. The USACE constructed fourteen artificial cutoffs and allowed two natural cutoffs to develop between 1929 and 1942 on the LMR. This shortened the river between Memphis, TN, and Old River, LA, by approximately 152 miles. Between 1932 and 1955, chute cutoffs constructed at 40 locations between Cairo, IL, and Natchez, MS, further shortened the river by another 55 miles. Following the cutoffs, the river attempted to regain some of its length through increased meandering, but according to Winkley (1977), the length increases were offset by the chute cutoffs so that the river is still approximately 150 miles shorter than prior to the cutoffs. This shortened and over-steepened river caused dramatic stage decreases throughout the river. Thus, the cutoffs have had the greatest morphological effect on the Mississippi River of any natural or anthropogenic feature on the recent morphology of the Mississippi River (USACE 1982; Elliott et al. 1991).

A summary of post-cutoff stage trends for high, mid-range, and low flows is provided in Table 6.1. The start and end dates for the three periods identified in Table 6.1 were selected to maximize lengths of the periods 
between abrupt changes in the specific stage records. In the MMR, records do not begin until the 1930s, and there were no meander cutoffs in this reach of the river. Consistent trends in stages were recognized as extending from the 1930 s to the present day. In the upper course of the LMR, between Columbus and Natchez where the cutoffs occurred, the post-cutoff period extends from the late-1950s to present. In the lower course of the LMR, between Red River Landing and Donaldsonville, there was an abrupt upward shift in the stages in the mid-1970s. Therefore, the time period for these stations extends from the mid-1970s to present day.

Table 6.1. General stage trends on the Mississippi River in the post-cutoff period.

\begin{tabular}{|c|c|c|c|c|c|c|}
\hline \multirow[b]{2}{*}{ Reach (time period) } & \multirow{2}{*}{\multicolumn{3}{|c|}{ Station Name }} & \multicolumn{3}{|c|}{ Stage Trends } \\
\hline & & & & $\begin{array}{l}\text { High } \\
\text { Flows }\end{array}$ & $\begin{array}{c}\text { Mid-range } \\
\text { Flows }\end{array}$ & $\begin{array}{l}\text { Low } \\
\text { Flows }\end{array}$ \\
\hline \multirow{3}{*}{$\begin{array}{l}\text { MMR (period } \\
\text { of record: } 1930 \text { s to } \\
\text { present day) }\end{array}$} & 1 & St. Louis & $\mathrm{MO}$ & DE & DE & SD \\
\hline & 2 & Chester & IL & $\mathrm{SI}$ & $\mathrm{DE}$ & SD \\
\hline & 3 & Thebes & IL & SI & DE & SD \\
\hline \multirow{13}{*}{$\begin{array}{l}\text { Upper course LMR } \\
\text { (post-cutoff period: } \\
\text { late-1950s to } \\
\text { present day) }\end{array}$} & 4 & Columbus & KY & $\mathrm{DE}$ & $\mathrm{DE}$ & $\mathrm{DE}$ \\
\hline & 5 & Hickman & KY & $\mathrm{DE}$ & SD & SD \\
\hline & 6 & Tiptonville & $\mathrm{TN}$ & $\mathrm{DE}$ & SD & SD \\
\hline & 7 & Caruthersville & $\mathrm{TN}$ & $\mathrm{DE}$ & SD & SD \\
\hline & 8 & Osceola & $\mathrm{TN}$ & $\mathrm{DE}$ & SD & D \\
\hline & & Memphis & $\mathrm{TN}$ & SD & D & D \\
\hline & & Helena & AR & SD & D & D \\
\hline & & Rosedale & MS & $\mathrm{DE}$ & SD & D \\
\hline & & Arkansas City & AR & SI & $\mathrm{DE}$ & SD \\
\hline & & Greenville & MS & SI & $\mathrm{DE}$ & SD \\
\hline & 18 & Lake Providence & $\mathrm{LA}$ & $\mathrm{DE}$ & DE & SD \\
\hline & & Vicksburg & MS & 1 & $\mathrm{SI}$ & DE \\
\hline & & Natchez & MS & 1 & I & $\mathrm{SI}$ \\
\hline \multirow{4}{*}{$\begin{array}{l}\text { Lower course LMR } \\
\text { (post-disturbance } \\
\text { period: mid-1970s } \\
\text { to present day) }\end{array}$} & & Red River Landing & $\mathrm{LA}$ & 1 & 1 & I \\
\hline & & Bayou Sara & $\mathrm{LA}$ & $\mathrm{DE}$ & DE & DE \\
\hline & & Baton Rouge & $\mathrm{LA}$ & $\mathrm{DE}$ & $\mathrm{DE}$ & $\mathrm{DE}$ \\
\hline & 25 & Donaldsonville & LA & $\mathrm{DE}$ & $\mathrm{DE}$ & $\mathrm{DE}$ \\
\hline
\end{tabular}

Table Legend

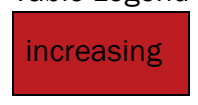

slightly


The types of trends evident in the stage records for high, mid-range, and low flows were broadly classified in Table 6.1 as increasing (I), slightly increasing (SI), dynamic equilibrium (DE), slightly decreasing (SD), or decreasing (D). The stage trend cells in Table 6.1 are labeled and colorcoded to assist readers in developing an overview of how the different types of trends are distributed through time and along the course of the Mississippi River.

These are initial, qualitative determinations based on visual interpretation of the specific gage records by the authors. At this preliminary stage, no attempt has been made to quantify the stage trends or to differentiate between different types numerically. Neither has statistical analysis of the stage records been conducted.

What this initial treatment has done is establish that trends that are consistent over different time periods can be identified in the records and that distinctive patterns can be seen in their spatial distribution along the Mississippi River. This demonstrates that the potential exists for both quantitative and statistical analyses to provide not only improved understanding of past trends and distributions of morphological change in the river but also valuable insights into the process-response mechanisms responsible for short- and long-term morphological changes. These insights will establish the basis for both explaining past responses and establishing causal links between natural and anthropogenic factors and the changes they have driven. Such developments would build the explanatory power needed to forecast morphological trends and behaviors, unlocking the possibility of moving from managing the river responsively to managing it adaptively.

The remainder of this discussion considers the implications of the initial assessment performed to date on a reach-by-reach and period-by-period basis.

\subsection{Trends in stages recorded in the MMR}

As shown in Table 6.1, a slight, decreasing trend can be detected in lowflow stages at all three stations in the MMR. This trend persists throughout the entire period of record, which starts in the 1930 s and continues to present day. Stages for mid-range flows fluctuate cyclically, but no long-term increasing or decreasing trends are discernible. High- 
flow stages have been relatively stable at St. Louis, but farther downstream at Chester and Thebes, they exhibit a slight, increasing trend.

\subsection{Trends in stages recorded in the LMR}

\subsubsection{Trends in stages recorded in the upper course of the LMR}

Because of the abrupt stage changes along the upper course of the LMR resulting from the meander cutoffs, it was necessary to separate the analysis of this portion of the river into the following three time eras.

1. The pre-cutoff period (begins during the nineteenth century and ends in the early-1930s) - In interpreting stage changes during the pre-cutoff period, it is important to note that, although periods of record at some stations extend back to the 1850 , data are generally sparse prior to the 1930 s and are especially limited during the nineteenth century.

2. The cutoff period (extends from the early-1930s to the mid-1950s) - The most abrupt stage reductions occurred during this period in association with the cutoffs.

3. The post-cutoff period (extends from the late-1950s to the present day) During this period, the morphology of the river has continued to adjust and evolve following the completion of the initial, abrupt responses to the cutoffs.

\subsubsection{Pre-cutoff period (1850s to early-1930s)}

The most complete data set for the pre-cutoff period comes from the Columbus gage, which has a period of record extending back to the mid1850s. The specific gage records for Columbus show that stages for all flows were increasing during the pre-cutoff period. High-flow stages at Memphis also appear to have risen, though scarcity of data makes it difficult to establish this with confidence. At Helena, Arkansas City, and Vicksburg, high-flow stages also appear to have been increasing during the pre-cutoff period. The limited data available for mid-range and low flows at these stations also suggest that stages may have increased. High-flow records for Natchez also suggest a possible increase in stages during the pre-cutoff period, although this cannot be stated with certainty because the data are limited. In summary, and recognizing the limitations of the available data, it appears that during the pre-cutoff period there were rising trends in stages (particularly for the high flows) in the upper course of the LMR between Columbus and Natchez. 


\subsubsection{Cutoff period (early-1930s to mid-1950s)}

The cutoffs resulted in the most abrupt and prolonged stage reductions observed in the Mississippi River during at least the last 100 years. The most dramatic response was recorded at Arkansas City where high-flow stages decreased by up to $15 \mathrm{ft}$. Stages immediately downstream, at Vicksburg, fell by 10 to $12 \mathrm{ft}$ during the cutoff period while those farther downstream at Natchez decreased by 4 to $5 \mathrm{ft}$, indicating that the impact of the cutoffs in lowering stages decreased with increasing distance downstream from the reach that experienced the most intense channel shortening. Stages at stations immediately upstream of the cutoffs (Helena, Mhoon Landing, and Star Landing) fell by 4 to $8 \mathrm{ft}$ during the cutoff period, but further upstream of the cutoffs, at Memphis, Fulton, and Osceola, stage reductions were smaller and much less abrupt. This indicates that the impact of the cutoffs in lowering stages also decreased with increasing distance upstream from the reach that experienced the largest number of cutoffs and most intense channel shortening. In the upper course of the LMR even farther upstream, between Caruthersville and Columbus, no changes in stage attributable to the cutoffs were detected. This indicates that the impact of the cutoffs in lowering stages had not progressed into the upper course of the LMR and did not affect the MMR farther upstream.

\subsubsection{Post-cutoff period (late-1950s to present day)}

During the post-cutoff period, although the upper course of the LMR continued to respond to the cutoffs, rates of change decreased dramatically. In addition, the river began adjusting to other factors such as maintenance dredging, and construction of dikes, revetments, levees, and diversions as well as changes in the hydrologic and sediment regimes resulting from the closure of upstream dams, tributary improvements, reductions in basin sediment yield due to improved soil conservation and hydrologic extremes.

It is not possible at this stage of the study to establish causal links between these factors and particular morphological responses, neither is it possible to rank their relative importance in driving the morphological changes observed in the river during the post-cutoff period. Nevertheless, it is useful to describe the general trends of stage change that occurred during the post-cutoff period. 
As shown in Table 6.1, stages have been relatively stable for both low and high flows at Columbus, the upstream-most station on the LMR. Just downstream, between Hickman and Caruthersville, there has been a slight decrease in low-flow stages, most of which has occurred since the 1980 s. In contrast, high-flow stages at these stations have been relatively stable during the post-cutoff period. Farther downstream between Osceola and Rosedale, there has been a dramatic, decreasing trend in low-flow stages. However, at high flows the only decreasing stages in this sub-reach were those at Memphis and Helena, with dynamic equilibrium prevailing upstream and increasing stages prevailing downstream. At Vicksburg and Natchez, a generally increasing trend is apparent for stages at both high and low flows except for low flows at Vicksburg, which seem to have been in dynamic equilibrium.

\subsubsection{Trends in stages recorded in the lower course of the LMR}

In the lower course of the LMR, between Red River Landing and Donaldsonville, there was an abrupt upward shift in the stages for all specific discharges in the mid-1970s. At Red River Landing (the first station in the lower course), an upward trend in stages for all flows has continued to the present day. Downstream of Red River Landing, between Bayou Sara and Donaldsonville, there have been some cyclic fluctuations, but overall the stages have been relatively stable since the mid-1970s.

\subsubsection{Overview of post-cutoff trends in stages in the LMR}

Although no attempt was made in this study to conduct a detailed analysis of the impacts of the numerous natural and anthropogenic factors responsible for driving morphologic trends in the river, it is clear from the specific gage records that complex morphologic adjustments have been and are still occurring throughout the river system, with the dominant factor being the meander cutoffs in the 1930 s and early-1940s. In fact, the specific gage records suggest that the river may be responding in a fashion typical of the adjustments expected in an alluvial stream subjected to a program of meander cutoffs, featuring decreasing stage trends (degradation) that migrate upstream from the reach with maximum disturbance and increasing stage trends (aggradation) that progress downstream from the reach with maximum disturbance. 
An overview of these post-cutoff trends is provided by the cumulative stage curves in Figures 6.1 and 6.2. These curves were developed for 12 stations (on the LMR) at low- and high-flow conditions using all the primary stations and a few secondary stations that were selected to help capture transition zones between the primary stations. The stations included were the following:

- Columbus (secondary station)

- Hickman (primary station)

- Caruthersville (secondary station)

- Osceola (secondary station)

- Memphis (primary station)

- Helena (primary station)

- Rosedale (secondary station),

- Arkansas City (primary station)

- Lake Providence (secondary station)

- Vicksburg (primary station)

- Natchez (primary station)

- Red River Landing (primary station).

Low flows selected for representation in the cumulative curves represent conditions when the water surface is close to the Low Water Reference Plane. Discharges selected to represent low-flow conditions ranged from $175,000 \mathrm{cfs}$ to $200,000 \mathrm{cfs}$. These curves are more indicative of changes in the elevation and morphology of the channel bed. High flows were selected to represent conditions around bankfull stage, and therefore, are more indicative of flood flow trends. Selected high flows ranged from $1,000,000$ cfs to $1,500,000 \mathrm{cfs}$.

These broad-scale stage trends along the MMR and LMR are also shown on the plan map in Figure 6.3. Comparison of the maps in Figure 6.3 clearly shows the contrasts between the high, mid-range, and low flow stages along the river. The low-flow trends are indicative of bed scour and fill on bed elevation changes while changes in mid-range flows result from changes to in-channel morphologic processes, and high-flow trends result from the additional influences of overbank and floodplain processes. In the LMR, these broad-scale, systematic adjustments are not, however, those of a freely adjusting, alluvial stream, being tempered by a variety of other factors such as dikes, revetments, levees, and alterations to the flow and sediment regimes. 


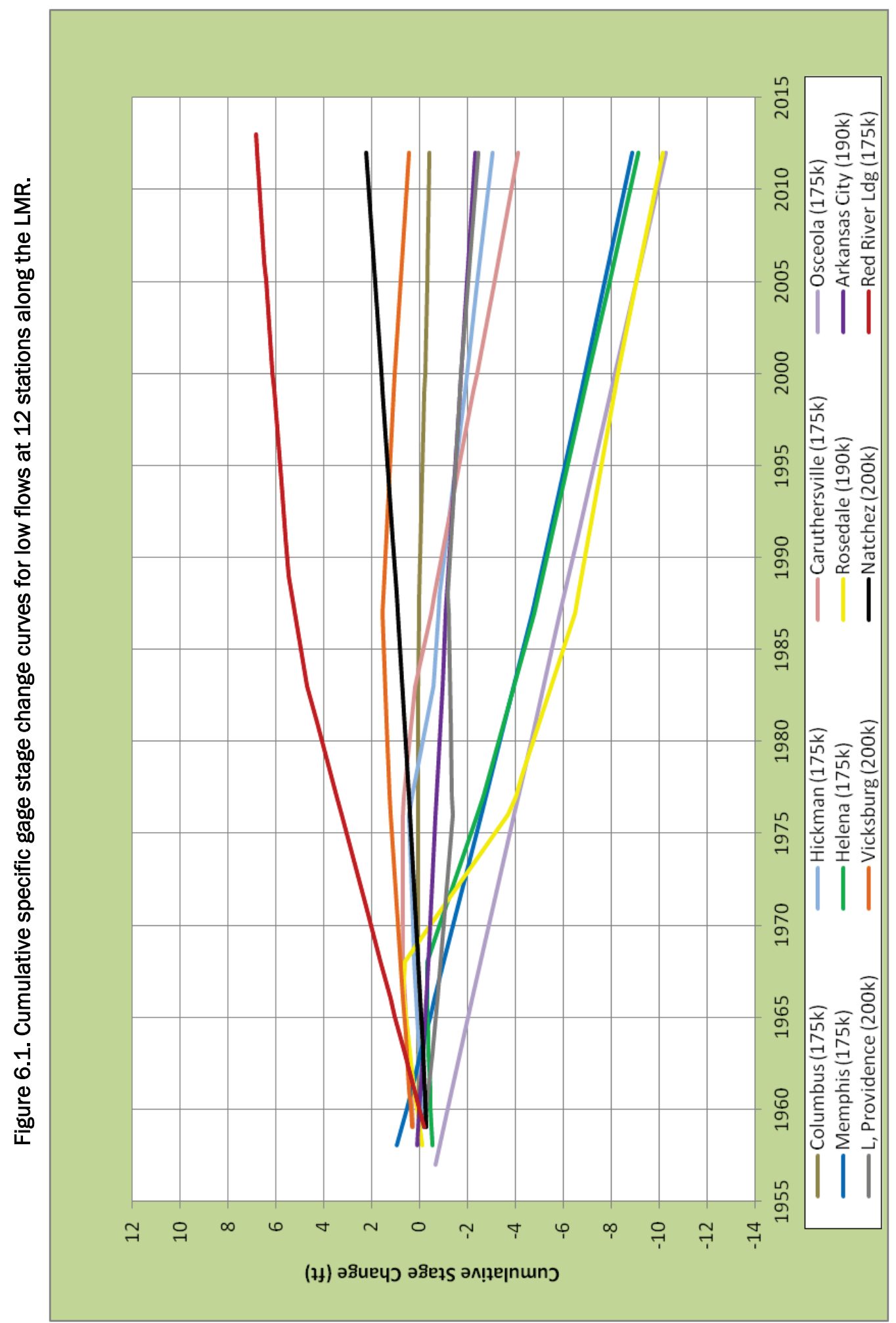




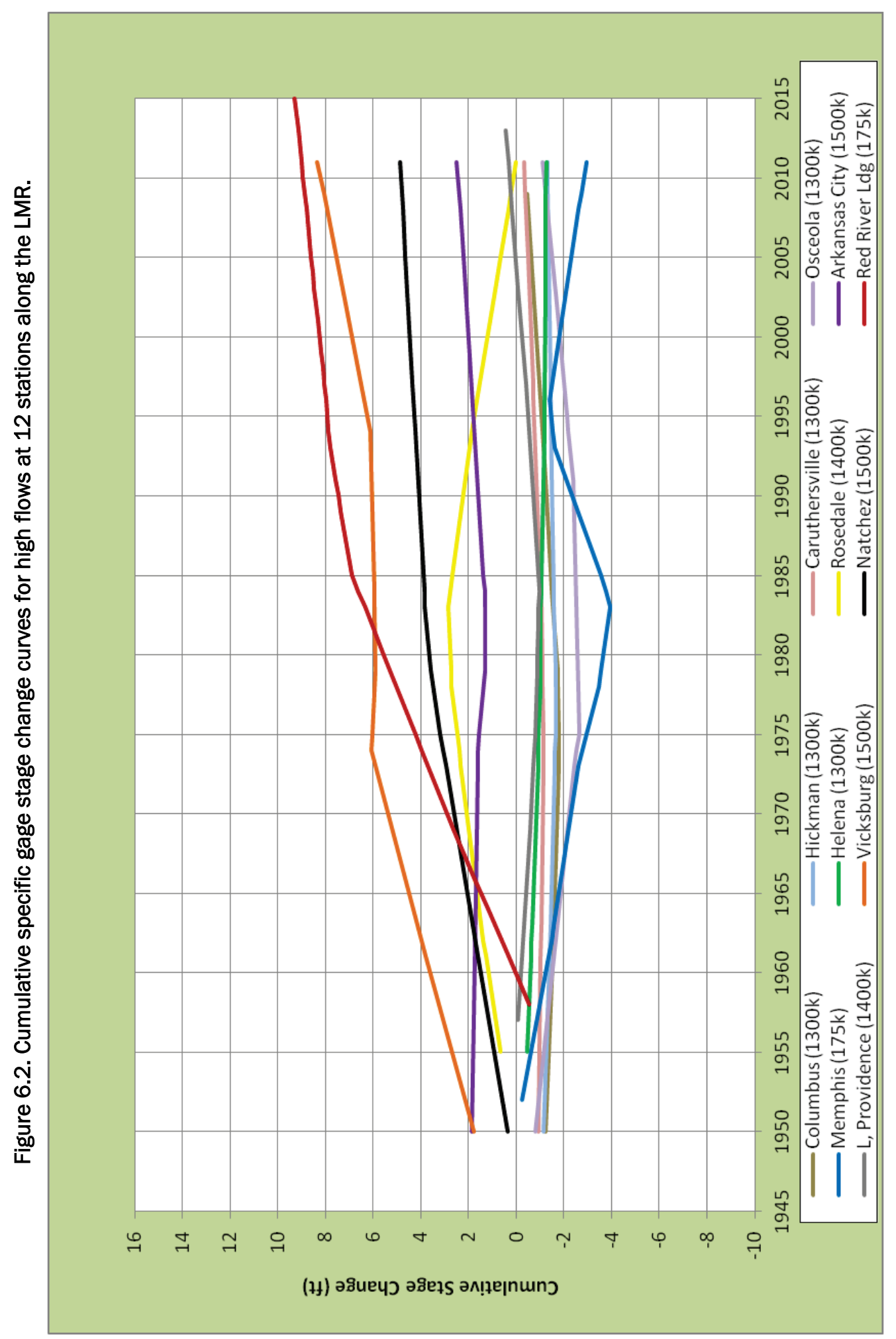


Figure 6.3. Broad-scale stage trends along the Mississippi River.
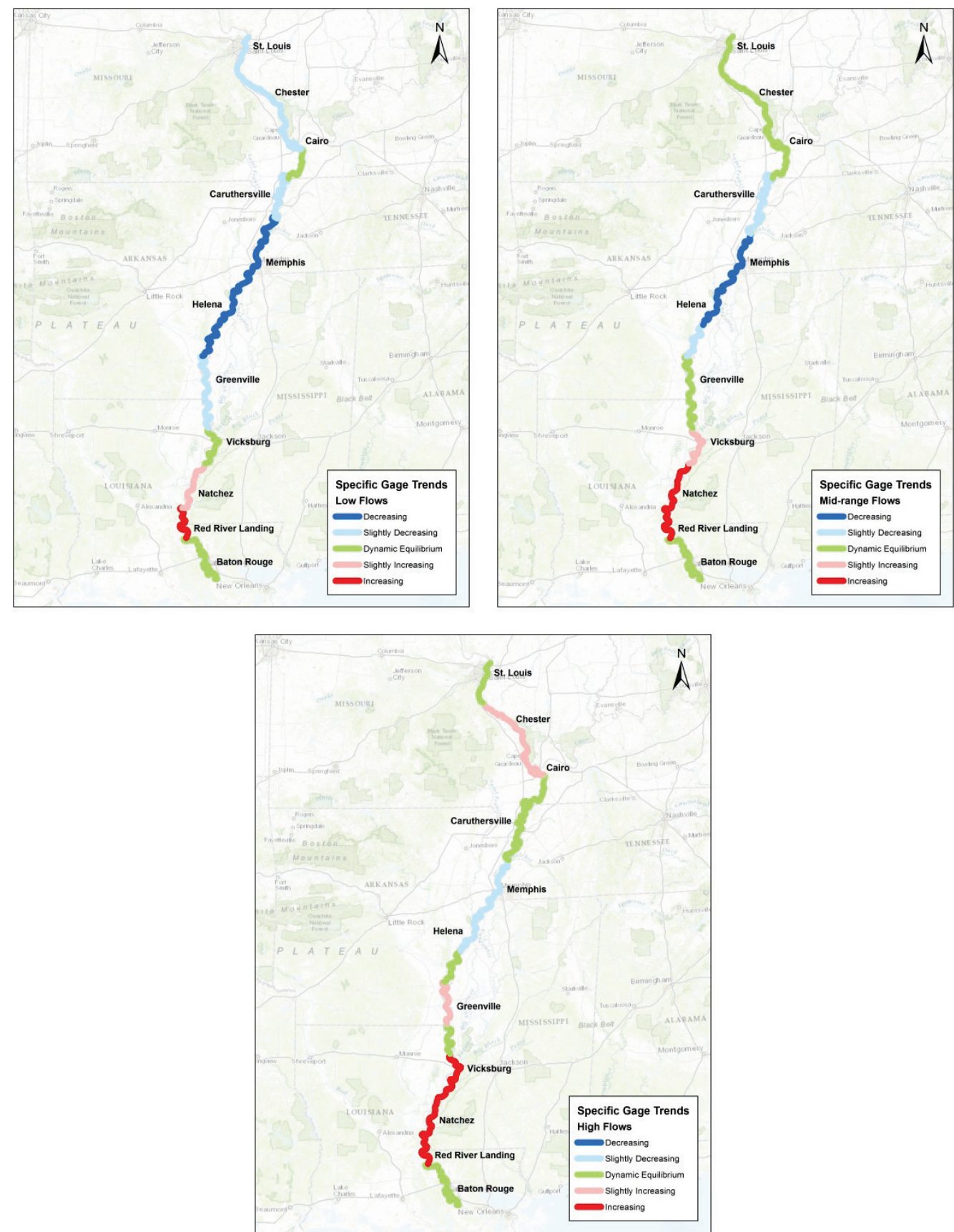


\section{Summary}

Understanding historical and present-day fluvial processes and morphological responses in the Mississippi River is essential to designing and delivering long-term management of the system for flood control, navigation, and ecology that is cost-effective, adaptable, and sustainable. Generation and initial assessment of specific gage records for 25 main stem hydrometric stations along the Mississippi River has demonstrated that complex morphologic adjustments have and are continuing to occur throughout the river system. Further, although no attempt was made in this study to conduct a detailed analysis of the effects of the numerous natural and anthropogenic factors on the morphologic trends in the river, inspection and preliminary analysis of the specific gage records developed in this study establish that they provide a powerful framework that when combined with other geomorphic assessment tools will aid in unraveling the complex fluvial processes that drive morphological change and evolution in the Mississippi River. 


\section{References}

Blench, T. 1966. Mobile-bed fluviology: A regime theory treatment of rivers for engineers and hydrologists. Edmonton, Alberta, Canada: The University of Alberta Press.

Cleveland, W. S., and S. J. Devlin. 1988. Locally-weighted regression: An approach to regression analysis by local filling. Journal of American Statistical Association 83(403):596-610.

Elliott, C. M, R. R. Rentschler, and J. H. Brooks. 1991. Response of the Lower Mississippi River low-flow stages. Edited by S.-S. Fan and Y.-H. Kuo, 4-16 - 4-23, Volume 1 (Section 4). In Proceedings of the Fifth Federal Interagency Sedimentation Conference, March 18-21, Las Vegas, NV.

Moore, N. R. 1972. Improvement of the Lower Mississippi River and tributaries, 1931 1972. November. Vicksburg, MS: Department of the Army, Corps of Engineers, U.S. Army, Mississippi River Commission.

U.S. Army Corps of Engineers (USACE). 1982. Analysis of major parameters affecting the behavior of the Mississippi River. Potamology Program (P-1), Report 4, December. Edited by J. R. Tuttle and W. Pinner. Vicksburg, MS: U. S. Army Engineer Division, Lower Mississippi Valley, Potamology Branch.

U.S. Congress. 1928. Flood Control Act of 1928: An act for the control of floods on the Mississippi River and its tributaries, and for other purposes. Seventieth Congress, Session I, Chap. 569, approved May 15. Washington, DC.

Watson, C. C., D. S. Biedenharn, and C. R. Thorne. 2013. Analysis of the impacts of dikes on flood stages in the Middle Mississippi River. Journal of Hydraulic Engineering 139(10):1071-1078. DOI: 10.1061/(ASCE)HY.1943-7900.0000786.

Winkley, B. R. 1977. Man-made cutoffs on the Lower Mississippi River, conception, construction, and river response. Potamology Investigations Report 300-2, March. Vicksburg, MS: U.S. Army Corps of Engineers, Waterways Experiment Station. 


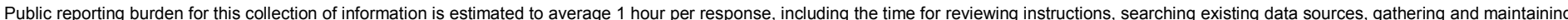

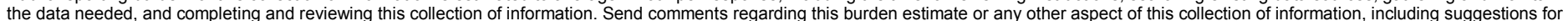

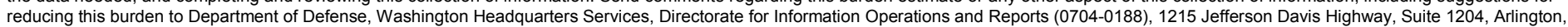

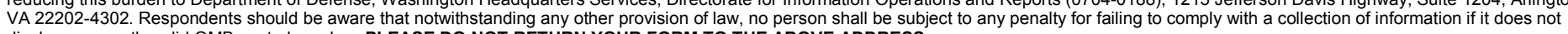
display a currently valid OMB control number. PLEASE DO NOT RETURN YOUR FORM TO THE ABOVE ADDRESS.

\begin{tabular}{|l|l|l}
\hline 1. REPORT DATE (DD-MM-YYYY) & 2. REPORT TYPE & 3. DATES COVERED (FrOm - To)
\end{tabular}

July 2017

Final 2014-2015

\section{TITLE AND SUBTITLE}

Large-scale Geomorphic Change in the Mississippi River from St Louis, MO, to

Donaldsonville, LA, as Revealed by Specific Gage Records

\section{5a. CONTRACT NUMBER}

$\mathrm{N} / \mathrm{A}$

5b. GRANT NUMBER

N/A

5c. PROGRAM ELEMENT NUMBER

$\mathrm{N} / \mathrm{A}$

\section{AUTHOR(S)}

5d. PROJECT NUMBER

127672

David S. Biedenharn, Mead A. Allison, Charles D. Little, Jr., Colin R. Thorne, and Chester C. Watson

5e. TASK NUMBER

$\mathrm{N} / \mathrm{A}$

5f. WORK UNIT NUMBER

$\mathrm{N} / \mathrm{A}$

\section{PERFORMING ORGANIZATION NAME(S) AND ADDRESS(ES)}

8. PERFORMING ORGANIZATION REPORT NUMBER

Biedenharn Group, LLC

Vicksburg, MS 39180

MRG\&P Report No. 10

9. SPONSORING / MONITORING AGENCY NAME(S) AND ADDRESS(ES)

U.S. Army Corps of Engineers, Mississippi Valley Division

10. SPONSOR/MONITOR'S ACRONYM(S)

MVD

Mississippi River Geomorphology and Potamology Program

1400 Walnut Street

11. SPONSOR/MONITOR'S REPORT NUMBER(S)

Vicksburg, MS 39180

\section{DISTRIBUTION / AVAILABILITY STATEMENT}

Approved for public release; distribution is unlimited.

\section{SUPPLEMENTARY NOTES}

Report series: Mississippi River Geomorphology \& Potamology (MRG\&P)

\section{ABSTRACT}

Specific gage records were developed for 25 stations on the Mississippi River between St. Louis, MO, and Donaldsonville, LA. Generation and initial inspection of these records for the Mississippi River establishes that complex morphologic adjustments have occurred throughout the river system for at least a century and indicates that these adjustments continue to the present day. Further, although no attempt was made in this study to conduct a detailed analysis of the effects of the numerous natural and anthropogenic factors on the morphologic trends in the river in the initial assessment reported herein, preliminary evaluation of the specific gage records demonstrates that they provide a powerful framework that, when combined with other geomorphic assessment tools, will aid in understanding and explaining the complex morphological processes that drive the Mississippi River. These and other comprehensive analyses are planned for future Mississippi River Geomorphology \& Potamology (MRG\&P) Program efforts.

\section{SUBJECT TERMS}

Potamology

River engineering

16. SECURITY CLASSIFICATION OF:

a. REPORT

Unclassified

\section{b. ABSTRACT}

Unclassified
River morphology

Mississippi River

Gages-Data processing

\section{c. THIS PAGE}

Unclassified

\section{LIMITATION OF ABSTRACT}

18. NUMBER OF PAGES

None
Geomorphology

River science 